\title{
ANATOMY OF A LOCAL-SCALE DROUGHT: APPLICATION OF Assimilated Remote Sensing Products, Crop Model, And Statistical Methods to an Agricultural Drought Study
}

Manuscript to be submitted to the Journal of Hydrology - Special Issue on Drought

Ashok K. Mishra ${ }^{1}$, Amor V.M. Ines ${ }^{2}$, Narendra N. Das ${ }^{3}$, C. Prakash Khedun ${ }^{4}$, Vijay P. Singh ${ }^{5}$, Bellie Sivakumar $^{6}$, James W. Hansen ${ }^{7}$

1202 B Lowry Hall, Glenn Department of Civil Engineering, Clemson University, Clemson, SC 29634, USA. Email: ashokm@clemson.edu; akm.pce@gmail.com

${ }^{2}$ International Research Institute for Climate and Society, The Earth Institute at Columbia University, 61 Route 9W, Palisades, NY 10964, USA. Email: ines@iri.columbia.edu

3Jet Propulsion Laboratory, M/S 300-323, 4800 Oak Grove Drive, Pasadena, CA 91109, USA. Email: Naraindra.N.Das@jpl.nasa.gov

4 Department of Biological \& Agricultural Engineering, Water Management \& Hydrological Science, 321E Scoates Hall, 2117, Texas A\&M University, College Station, TX 77843, USA. Email: pkhedun@tamu.edu; pkhedun@gmail.com

5 Department of Biological \& Agricultural Engineering, Zachry Department of Civil Engineering, Water Management \& Hydrological Science, 321 Scoates Hall, 2117, Texas A\&M University, College Station, TX 77843, USA. Email: vsingh@tamu.edu

${ }^{6}$ School of Civil and Environmental Engineering, University of New South Wales, Vallentine Annexe (H22), Level 1, Room VA139, Kensington Campus, Australia. Email:

s.bellie@unsw.edu.au.

${ }^{7}$ International Research Institute for Climate and Society, The Earth Institute at Columbia University, 61 Route 9W, Palisades, NY 10964, USA. Email: jhansen@iri.columbia.edu

Corresponding author: Ashok K. Mishra (ashokm@clemson.edu; akm.pce@gmail.com) 


\section{Abstract}

2 Drought is of global concern for society but it originates as a local problem. It has a significant

3 impact on water quantity and quality and influences food, water, and energy security. The

4 consequences of drought vary in space and time, from the local scale (e.g. county level) to

5 regional scale (e.g. state or country level) to global scale. Within the regional scale, there are

6 multiple socio-economic impacts (i.e., agriculture, drinking water supply, and stream health)

7 occurring individually or in combination at local scales, either in clusters or scattered. Even

8 though the application of aggregated drought information at the regional level has been useful in

9 drought management, the latter can be further improved by evaluating the structure and evolution

10 of a drought at the local scale. This study addresses a local-scale agricultural drought anatomy in

11 Story County in Iowa, USA. This complex problem was evaluated using assimilated AMSR-E

12 soil moisture and MODIS-LAI data into a crop model to generate surface and sub-surface

13 drought indices to explore the anatomy of an agricultural drought. Quantification of moisture

14 supply in the root zone remains a grey area in research community, this challenge can be partly

15 overcome by incorporating assimilation of soil moisture and leaf area index into crop modeling

16 framework for agricultural drought quantification, as it performs better in simulating crop yield.

17 It was noted that the persistence of subsurface droughts is in general higher than surface

18 droughts, which can potentially improve forecast accuracy. It was found that both surface and

19 subsurface droughts have an impact on crop yields, albeit with different magnitudes, however,

20 the total water available in the soil profile seemed to have a greater impact on the yield. Further,

21 agricultural drought should not be treated equal for all crops, and it should be calculated based

22 on the root zone depth rather than a fixed soil layer depth. We envisaged that the results of this

23 study will enhance our understanding of agricultural droughts in different parts of the world. 
Key words: Drought anatomy, Data assimilation, Crop yield, Copulas, Root zone soil moisture

\section{1. Introduction}

26 There is a continuous rise in water demand in many parts of the world in order to satisfy the

27 needs of growing population, rising agricultural demand, and increasing energy and industrial sectors (Mishra and Singh, 2010; Singh et al., 2014). These growing water demands are further challenged by the impact of droughts. Drought propagates through water resources systems in virtually all climatic zones, as it is driven by the stochastic nature of hydroclimatic variables. Based on the Fifth Assessment Report of the Intergovernmental Panel on Climate Change (IPCC, 2013), the atmospheric temperature measurements show an estimated warming of 0.85 degree Celsius since 1880 and each of the last three decades has been successively warmer at the Earth's surface than any preceding decade. It is anticipated that future global warming and climate change will have impact on average precipitation, evaporation, and runoff, that happen to be controlling factors for different types of droughts. Drought is well considered to be a global concern, since about half of the earth's terrestrial surfaces are susceptible (Kogan, 1997), and it had the greatest detrimental impact among all natural hazards during the $20^{\text {th }}$ century (Bruce, 1994; Obasi, 1994).

Meteorological records indicated that major droughts have been observed in all continents,

41 affecting large areas in Europe, Africa, Asia, Australia, South America, Central America, and 42 North America (Mishra and Singh, 2010). A number of drought studies have been carried out to 43 investigate drought characteristics using data from multiple sources at the global scale (Sheffield and Wood, 2007; Dai, 2010; Vicente-Serrano et al., 2010 ; Van Lanen et al., 2013; Wada et al., 2013 ), national and regional scales (Rajsekhar et al., 2014; Hao and Aghakouchak, 2014; Zhang 
47 river basin levels (Tallaksen et al., 2009; Mishra and Singh, 2009; Madadgar and Moradkhani, 48 2011; Van Loon et al., 2014; Zhang et al., 2012).

49 Over the past several decades, there has been a significant improvement in the development of 50 drought indices to quantify drought events, each with its own strengths and weaknesses (Mishra 51 and Singh, 2010). The commonly used indices are: Palmer Drought Severity Index (PDSI; 52 Palmer, 1965), Crop Moisture Index (CMI; Palmer, 1968), Bhalme and Mooly Drought Index 53 (BMDI; Bhalme and Mooley, 1980), Surface Water Supply Index (SWSI; Shafer and Dezman, 54 1982), Standardized Precipitation Index (SPI; McKee et al., 1993), Reclamation Drought Index 55 (RDI; Weghorst, 1996), Soil Moisture Drought Index (SMDI; Hollinger et al., 1993), Vegetation 56 Condition Index (VCI; Liu and Kogan, 1996), and Drought Monitor (Svoboda et al., 2002). 57 Comprehensive reviews of drought indices can be found in Heim (2002) and Mishra and Singh 58 (2010). However, the challenge still remains for deriving drought indices because of the 59 uncertainty due to scaling issues to capture detailed information instead of aggregated 60 information within spatial units. In a real-world scenario, it is often noticed that within the

61 regional scale, there are multiple socio-economic impacts (i.e., agriculture, drinking water 62 supply, ecosystem health, hydropower, waste disposal, and stream health) occurring at local 63 scales individually or in combination, either located in clusters or scattered. Therefore, to reduce 64 the socio-economic impacts of a drought, the anatomy of drought needs to be understood at a 65 local scale for near real-time drought management.

\subsection{Importance of local-scale drought studies}

67 With the advancement in technology (e.g., remote sensing, climate forecasts), significant 68 improvement is made in drought identification, monitoring, and with reasonable accuracy in 69 forecasting (Mishra and Singh, 2010) at a regional to global scale by aggregating hydroclimatic 
fluxes as well as land surface characteristics. However, drought management can be improved by

71 understanding and quantifying the triggering variables at a local scale. The local-scale drought

72 analysis can partly overcome large amounts of uncertainties due to scale issues, model

73 parameter, data quality, non-availability of socio-economic information, missing microscale

74 climate, and catchment information. The local-scale drought is a subset of regional- or global-

75 scale drought, that needs special attention to improve water management. For example, drought

76 varies with space and time within a river basin (Mishra and Singh, 2009); and there are specific

77 sub-basins where drought is frequent, that needs local-scale treatment to improve water

78 management within the watershed. Similarly, agricultural drought is mainly driven by stochastic

79 and heterogeneous soil moisture, that poses a challenge to generate subsurface drought (soil

80 moisture) information. However, with recent development of Soil Moisture Active and Passive

81 (SMAP) mission products, it is expected that the robustness of agricultural drought monitoring

82 and forecasting information will improve. Our focus in this study is limited to local-scale

83 agricultural drought analysis to improve agricultural water management.

84 Application to agricultural drought: Different crops are grown in different parts of the world,

85 regions, and even within the same watershed. When compared with that of other types of

86 drought, agricultural drought quantification is not as straightforward due to several reasons, for

87 example, crop water requirements are different for different crops, which make it complex to

88 quantify drought appropriately. Here, crop water requirement is defined as the amount of water

89 needed by the crop to grow optimally and to compensate for the loss through evapotranspiration.

90 Given a drought situation, different crops will behave differently, which means the drought for

91 one type of crop may not represent the same condition for other types of crop (i.e., drought for

92 crop may not be a drought condition for another crop). The agricultural drought will differ 
93 between crops because of two major factors (demand and supply), that are discussed in the 94 following section:

95 (A) Crop water demand: The agricultural drought index should be represented by the crop 96 water availability during the growing season, that varies among crops and seasons. This is 97 governed by several factors (FAO; http://www.fao.org/docrep/s2022e/s2022e07.htm):

98 (a) Climate factors: Comparatively higher crop water needs are found in areas that are 99 hot, dry, windy, and sunny. Climate factors also influence the duration of the total 100 growing period and the various growth stages;

101 (b) Crop type: Higher leaf area (example: maize) will be able to transpire and, thus, use more water than the reference grass crop; (c) Growth type: Crops that are fully developed will require more water than those at growth stages;

(d) Total growing period: This is an important variable, as it mostly depends on local 106 circumstances (e.g. local crop varieties). The growing periods largely differ, depending on the type of crops, for example, sugarcane (270-365 days), maize grain (125-180 108 days), cotton (180-195 days), and sunflower (125-130 days). The total growing period (T) also determines crop growth stages, that include initial stage $(0.1 \mathrm{~T})$, crop development stage ( 0.7 to $0.8 \mathrm{~T})$, and mild to late season stage ( 0.1 to $0.2 \mathrm{~T})$; (e) Crop water needs: This information needs to be collected at local scale, as it is driven by several factors $(\mathrm{a}-\mathrm{d})$. For example, maize needs $500-800 \mathrm{~mm}$ of water, sunflower needs $600-1000 \mathrm{~mm}$ of water, whereas sugarcane needs $1500-2500 \mathrm{~mm}$ of water; and 
(f) Drought resistance: Some of the crops are more sensitivity to drought in comparison to others, for example, crops with low sensitivity (cotton), medium to high sensitivity (maize), and high sensitivity (potato and sugarcane).

(B) Crop water supply: The water is supplied to crops by the soil moisture available in the root zone. Therefore, to quantify an agricultural drought index, the relationship between water extraction and root zone needs to be understood. In general, more water is extracted from the top layer in comparison to the bottom layers. For example, in the case of corn (Figure 1), the typical extraction pattern follows 4-3-2-1 rule (Kranz et al., 2008). This means that the top $1 / 4^{\text {th }}$ of the root zone supplies $40 \%$ of the water, the next $1 / 4^{\text {th }}$ of the root zone supplies $30 \%$ of the water, and so on. Typically, the corn root depth can reach up to $180 \mathrm{~cm}$, however, in some cases during late season the conservative management assumes a $90 \mathrm{~cm}$ effective root zone. The root depth, that supplies moisture for crop growth, differs between crops; therefore, soil moisture commonly used for agricultural drought monitoring should be driven by the root zone depth instead of a fixed depth. This means, identifying the number of layers will play an important role for quantifying agricultural droughts.

Previous agricultural drought research considered uniform depth of soil moisture for all types of available crops to quantify agricultural drought scenarios. However, as discussed above, the moisture available in different layers and root zone depth will play an important role for the quantification of agricultural drought. The other advancement that will be made in this study is to explore the improvement made by a data assimilation-crop modeling framework by including remotely-sensed soil moisture and leaf area index for agricultural drought research. Therefore, the overall aim of this study is to evaluate the anatomy of a local-scale drought. This is done through the following specific objectives: (a) identification of the best data assimilation-crop 
137 modeling framework under different schemes for agricultural drought quantification; (b) 138 generation of surface and subsurface drought indices useful for local-scale drought analysis; (c) 139 characterization of the behavior of surface and subsurface droughts and extraction of useful 140 information for future agricultural water management; and (d) quantification of the impact of 141 surface and subsurface drought properties. Here, the agricultural drought was analyzed, 142 considering maize as a crop product.

143 2. Experimental set up

144 This experiment uses a combination of models (Figure 2a) to help us mine the possible 145 relationship that may exist between the different variables and to quantify the physical process in 146 the local scale agricultural droughts. For this study, we applied our modeling framework to 147 study the anatomy of a local-scale agricultural drought and its impact on maize yields in Story 148 County, Iowa, USA. The following section briefly describes different components used to 149 develop the modeling framework.

\subsection{Crop model-data assimilation framework}

151 Assimilating remote sensing data into a crop simulation model by means of in-season filtering 152 (e.g., Kalman or particle filters) is a relatively new area of research in agricultural modeling (de 153 Wit \& van Diepen, 2007; Vazifedoust et al., 2009; Ines et al., 2013). Remote sensing data of soil 154 moisture and vegetation (e.g., LAI - Leaf Area Index, NDVI - Normalized Difference 155 Vegetation Index, etc.) are now available at regular time intervals and spatial resolutions that can 156 be used effectively in a crop model to better estimate aggregate yields. Assimilation of remote 157 sensing data helps improve the water- and energy-budget simulation in the crop model. 158 However, assimilation of remote sensing data into a physiologically-based crop model is not as 159 straightforward as it seems, because when one variable is adjusted the other dependent variables 160 must be also updated. For example, when remotely sensed LAI data is assimilated into the crop 
161 model, other model variables, like biomass and leaf weight, need to be adjusted as well. In the 162 case soil profile moisture, which is physically connected with the surface soil moisture, nudging 163 is also needed when remotely-sensed near-surface soil moisture data is assimilated in the crop 164 model.

165 To accommodate the above-mentioned requirements for a crop model-data assimilation, it is 166 essential to customize the crop model to work in a data assimilation framework. This includes 167 stopping the model at daily time step or when remote sensing data is available for assimilation 168 and then restarting it for the next day (the so-called the 'stop-and-start mechanism') without 169 going back to the time the seed was sown. This stop-and-start mechanism requires saving all the 170 relevant variables in physical files, such that the model can remember their current values when 171 invoked to run again by accessing these auxiliary files and reading the variables' values on run172 time. This capability enables the assimilation of remote sensing data whenever available and also 173 allows the updating of the related model variables by the remote sensing variable subsequently.

174 We developed a variant of the Ensemble Kalman Filter (EnKF), called Ensemble Square Root 175 Filter (Whitaker and Hamill, 2002), to simplify the use of remotely-sensed data in the data 176 assimilation procedure. The square root filter allows data assimilation without perturbing the 177 observed data; this is particularly appealing when assimilating growth variables, e.g., LAI. 178 Details of the crop model-data assimilation framework are provided in Ines et al. (2013) and the 179 data flow and assimilation steps are illustrated in Figure 2b. Forty ensemble members were 180 created for the data assimilation experiments using observed variability in soils and crop cultivar 181 characteristics. Planting density and management practices (i.e., planting and fertilizer) were 182 kept fixed based on publications for maize in Central Iowa. The crop model-data assimilation 183 framework consists of EnKF and a modified DSSAT-CSM-Maize (Jones et al., 2003; Ines et al., 
185 Four major cases were explored in the crop model-data assimilation: open-loop (no data 186 assimilation); and three runs using remotely-sensed (RS) data - soil moisture (SM) assimilation

187 only, LAI assimilation only, and assimilating both SM and LAI data. Results of these 188 experiments allow us to assess the utility of RS data assimilation for better estimation of 189 aggregate yields, as compared to open-loop simulation alone, as well as to evaluate the utilities 190 of those RS variables in the data assimilation and in the study of local scale drought.

191 Data used: Remote sensing data that were used in the experiments include MODIS-LAI (1 x 1 $192 \mathrm{~km}{ }^{-2}, 8$-day composite resolution; http://reverb.echo.nasa.gov/reverb/), AMSR-E near-surface 193 soil moisture (Njoku et al., 2003; $25 \times 25 \mathrm{~km}^{-2}$, daily resolution (only descending); 194 http://nsidc.org/data/amsre//); county maize yield data were derived from USDA-NASS 195 (http://www.nass.usda.gov); soil data were derived from SSURGO (http://www.nrcs.usda.gov); 196 weather and auxiliary data were taken from Iowa State University AgClimate mesonet 197 (http://mesonet.agron.iastate.edu/agclimate/) and their Extension and Outreach office's 198 publications for maize in Central Iowa (http://www.extension.iastate.edu). Simulations were 199 done for the 2003-2009 period.

\subsection{Drought indices}

201 The drought indices are the prime variable for assessing the effect of a drought and for defining 202 different drought parameters, which include intensity, duration, severity, and spatial extent. The 203 most commonly used timescale for drought analysis is a month, however, we have used weekly 204 timescale during crop periods to evaluate the agricultural drought. The drought indices are 205 calculated based on fitting a suitable probability density function for the time series, which is 206 then transformed to a normal distribution so that the mean SPI for the location and desired period 
207 is zero (McKee et al., 1993). The drought indices are classified in two categories: (a) surface 208 drought indices, and (b) subsurface drought indices. A brief discussion of these is provided next.

209 Surface drought indices: The surface drought indices are derived by surface hydroclimatic 210 fluxes (i.e., precipitation, evapotranspiration and runoff), as shown in Figure 3. When 211 precipitation is standardized to quantify a drought, it is called Standardized Precipitation Index 212 (SPI). To develop a drought index, relatively longer data sets will be useful. Here, we have used 213 weekly timescale due to two reasons: (i) it will better quantify the dynamics of moisture supply 214 and demand for an agricultural drought scenario; and (ii) it will overcome some limitations of 215 length of data, which are often witnessed in the application of remote sensing products (Njoku et 216 al., 2003). The derivation of SPI based on weekly rainfall at different temporal resolution $(1,2$, 2173,4 weeks) leads to the generation of corresponding SPI time series, SPI1, SPI2, SPI3 and SPI4.

218 Subsurface drought indices: The subsurface drought indices are derived by subsurface 219 hydrologic fluxes, which are mostly quantified by the soil moisture available at different layers 220 (Figure 3). The soil profiles were set up in the crop model-data assimilation using nine layers $(0-$ $2215,5-15,15-30,30-45,45-60,60-90,90-120,120-150$, and 150-180 cm) for a depth of $180 \mathrm{~cm}$ 222 sampled in a Monte Carlo way from two dominant soil types in the county based on SSURGO 223 data. Subsurface drought indices are relatively complex in comparison to the surface drought 224 indices due to challenges involved in determining: (a) moisture available in different layers; and 225 (b) root zone depth is different between crops - this makes it difficult to identify depths of soil 226 layers corresponding to the root zone depth for agricultural drought analysis. We have selected 227 different subsurface drought indices, that vary with soil layer depth (i.e., $1^{\text {st }}$ layer, $2^{\text {nd }}$ layer, ...) 228 as well as with temporal resolution (i.e., 1- to 4-week temporal scale). The selected drought 229 indices are: 
(a) Standardized Soil Moisture Index for Layer 1 (SSMI_L1): This corresponds to the amount of soil moisture available in the top layer (0 to $5 \mathrm{~cm})$. The SSMI_L1 is calculated for 1 to 4 weeks of temporal resolution, that are denoted by SSMI1_L1, SSMI2_L1, SSMI3_L1, and SSMI4_L1.

(b) Standardized Soil Moisture Index for Layer 2 (SSMI_L2): This corresponds to the amount of soil moisture available in the $2^{\text {nd }}$ layer $(5$ to $15 \mathrm{~cm})$. The SSMI_L2 is calculated for 1 to 4 weeks of temporal resolution, that are denoted by SSMI1_L2, SSMI2_L2, SSMI3_L2 and SSMI4_L2.

(c) Standardized Soil Moisture Index for Layer 3 (SSMI_L3): This corresponds to the amount of soil moisture available in the $3^{\text {rd }}$ layer $(15$ to $30 \mathrm{~cm})$. The SSMI_L3 is calculated for 1 to 4 weeks of temporal resolution, that are denoted by SSMI1_L3, SSMI2_L3, SSMI3_L3 and SSMI4_L3.

(d) Standardized Soil Water Availability Index (SSWI): This corresponds to the amount of soil water available in all the soil layers $(0$ to $180 \mathrm{~cm})$ considered for the analysis. The SSWI is calculated for 1 to 4 weeks of temporal resolution, that is denoted by SSWI1, SSWI2, SWI3 and SSWI4. The soil water varies for different layers and there is also a feedback mechanism that works to supply moisture from the bottom layer to the top layer due to the suction properties of root system and the pressure differentials caused by atmospheric demand. Therefore, using higher depth $(180 \mathrm{~cm})$ may provide aggregated information of soil moisture, which could be used during drought scenarios.

\subsection{Analysis of drought and yield relationship}

Drought-yield relationship is non-linear because of the complexity of water-yield relationship.

Crop sensitivities to water stress vary by crop development stage (Doorenbos and Kassam, 1979;

Steduto et al., 2012; Mishra et al., 2013). When a drought event occurs at the non-sensitive stage 
254 of crop growth, the impact may not be as substantial as when the drought event happened at the

255 sensitive crop growth stage (e.g., during flowering). The severity and duration of a drought event

256 may also define the extent of impact to the crops. For this local-scale drought analysis, we focus

257 on the impact of drought severity, duration, maximum severity, maximum duration, number of

258 events, and the temporal scales of these drought indices to maize yields in Story County, Iowa.

259 The uniqueness of this study lies in the parameters used to analyze the agricultural drought.

260 Agricultural drought indices were derived from soil moisture values of the first (SSMI_L1),

261 second (SSMI_L2) and third (SSMI_L3) soil layers and the total available water (SSWI)

262 simulated by the aggregate-scale crop model, while assimilating SM + LAI. Since the NASS

263 yield data were reported based only on average values, we opted to perform the drought-yield

264 analysis using the forty ensemble yield results from SM + LAI data assimilation, considering that

265 the results for 2008, which was a very wet year, may be excluded. Using the time series of yield

266 ensembles is important, because not all the spectra of yields may show the sensitivities to

267 drought events. We decomposed the yearly yield distributions, therefore, to $5^{\text {th }}$ percentile, $50^{\text {th }}$

268 percentile, and $95^{\text {th }}$ percentile, wherein we hypothesized that those lying in the $5^{\text {th }}$ percentile

269 category will show strong response to drought events. Correlation analysis was conducted to

270 determine the relationships among the drought indices mentioned above with yield categories at

271 different temporal scales (1, 2, 3 and 4 weeks).

\section{$272 \quad 2.4$ Application of statistical methods}

273 In this study, statistical methods were used to analyze the information generated from the

274 experiment. A brief discussion of the statistical methods employed is provided here:

275 Cross correlation analysis: A linear relationship between two sets of variables can be obtained

276 using cross-correlation analysis at different lags. In this study, cross-correlation analysis was 
277 employed to denote the influence of weekly rainfall on both surface and subsurface drought 278 indices at different temporal resolutions.

279 Mutual information: Mutual information (MI) measures the amount of information that can be 280 obtained about one random variable by observing another (Singh, 1997). For example, The 281 estimation of MI between two variables (X and $\mathrm{Y}$ ) depends on three probability distributions $282 \mathrm{p}(\mathrm{x}), \mathrm{p}(\mathrm{y})$, and $\mathrm{p}(\mathrm{x}, \mathrm{y})$. In this study, MI was calculated, based on the kernel density estimation, 283 that has several advantages over the traditional histogram based method (Mishra and Coulibaly, 284 2014). A high value of MI score would indicate a strong dependence between two variables. MI 285 can measure both linear and nonlinear dependency between variables. 286 Copulas: Multivariate analyses are often constrained by limitations of conventional functional 287 multivariate frequency distributions that assume that the marginals are from the same family of 288 multivariate distributions. The advantage of copula (Sklar, 1959) over classical multivariate 289 distributions is that it is not constrained by the statistical behavior of individual variables. In 290 hydrology, copula has been successfully used in flood studies (e.g. Chowdhary et al., 2011; 291 Zhang and Singh, 2007), multivariate drought frequency analysis (e.g. Khedun et al., 2012; 292 Shiau and Modarres, 2009), spatial mapping of drought variables (Rajsekhar et al., 2012), and in 293 modeling the influence of climate variables on precipitation (e.g. Khedun et al., 2013). The 294 methodology for copula selection and simulation adopted in this paper follows the one presented 295 by Genest and Favre (2007).

296 Wavelet analysis: There has been an extensive application of wavelet analysis to hydroloclimatic 297 time series (Kumar and Foufoula-Georgiou, 1997; Torrence and Compo, 1998; Labat, 2005; 298 Ozger et al., 2009; Mishra et al., 2011). In this study, the Continuous Wavelet Transform (CWT) 299 was used to decompose a signal into wavelets and generate frequency information at different 
temporal resolutions. Similarly, the cross wavelet transform (XWT) was used to detect the interactions between weekly rainfall and drought indices over multiple timescales by exposing the common power in time-frequency space.

303 Hurst exponent: The Hurst exponent $(\mathrm{H})$ is used to measure the persistence of a time series, that 304 either regresses to a longer term mean value or 'cluster' in a particular direction (Sakalauskienne, 305 2003; Mishra et al., 2009). The value of $\mathrm{H}$ ranges between 0 and 1, and it can be categorized into 306 two major categories: (a) a value between 0 to 0.5 indicates a random walk, where there is no 307 correlation between two present and future elements and there is a $50 \%$ probability that future 308 values will go either up or down - any series of this type are hard to predict; and (b) the value of $\mathrm{H}$ between 0.5 and 1 indicates persistent behavior, which means the time series is trending.

\section{3. Results and discussions}

\subsection{Performance of data assimilation schemes}

312 The data used in this study is the most readily available source of maize yield estimate for 313 aggregate modeling in the study area. The NASS mean yield for maize in Story Co., Iowa for the 314 2003-2009 period was $11.1 \mathrm{Mgha}^{-1}$ (standard Deviation of $0.7 \mathrm{Mgha}^{-1}$ ). The performance of 315 assimilation schemes is shown in Table 1. Without data assimilation (open-loop), it is apparent 316 that the crop model, even if applied in a Monte Carlo way, cannot estimate well the aggregate 317 yields, although it captures some of the interannual yield variability. For these experiments, we 318 intended to use data from only one station to represent the climate in the county, so that we can 319 test the hypothesis that assimilation of remotely-sensed soil moisture or vegetation could correct 320 the deficiencies contributed by model forcing, in this case, the scale effect of station rainfall. 321 Assimilation of remotely-sensed LAI alone did improve the yield performance from open-loop. 322 Assimilation of remotely-sensed SM did not improve the correlation from the LAI assimilation 
323 performance, but improved substantially the mean bias error in aggregate yield estimates. Ines et 324 al. (2013) noted that AMSR-E SM data assimilation during very wet years (e.g., 2008) tended to 325 completely minimize the water stress experienced by crops but had caused too much leaching of 326 nitrogen from the soil profile resulting in unrealistic reduction in yields. They attributed this crop 327 model-data assimilation behavior to the bias in AMSR-E soil moisture data, which new 328 generation soil moisture satellites may be able to address, e.g., the upcoming SMAP mission. 329 Assimilating both SM and LAI substantially improved the estimation of aggregate yields, 330 suggesting that correcting both the hydrologic and plant components of a field-scale crop model 331 applied at the aggregate scale to estimate aggregate processes is very important. If we apply a 332 composite of the data assimilation schemes (e.g., assimilating LAI or SM+LAI when they are 333 performing better), a better estimate of aggregate yield can be achieved with the crop data334 assimilation scheme. The mutual information between weekly rainfall and subsequent soil 335 moisture available at different layers was calculated using four schemes (open loop, SM 336 assimilation, LAI assimilation, and SM+LAI assimilation), as shown in Figure 4. It was observed that SM+LAI assimilation comparatively captured more information between weekly rainfall and

338 soil moisture in different layers and it is expected that this information could be potentially used 339 for drought propagation from surface to subsurface layers. Therefore, for this local-scale drought 340 analysis, we focused on analyzing the soil water fluxes generated by assimilating SM + LAI 341 (normal mode).

\section{$342 \quad 3.2$ Selection of drought indices}

343 The cumulative sum of precipitation during the crop growing periods of 2003-2009 is shown in

344 Figure 5. Based on visual inspection, three different patterns are noticed: (a) excess rainfall 345 during 2008; (b) deficit rainfall during 2006 and 2009; and (c) normal rainfall for 2003, 2004, 
2005, and 2007. The precipitation pattern differs between the years and this difference becomes more prominent during the growing stages of crops. This precipitation variability generates a series of wet and dry spells, that will impact the moisture availability for crop growth (Mishra et al., 2013). This study extends the analysis to improve drought indices associated with subsurface soil moisture, which evolves with precipitation variability during the crop period.

The standardized drought indices were derived from precipitation and hydrologic fluxes generated from the crop model-data assimilation (SM+LAI) framework consisting of the EnKF and a modified DSSAT-CSM-Maize crop model. Before deriving drought indices, it is important to identify suitable probability density functions (pdf) that fit the selected hydroclimatic variables. The pdfs of weekly precipitation and soil moisture generated for layer 1 of the soil profile are shown in Figure 6. Only a limited number of runoff events were generated at a weekly time scale, i.e., 16 weeks witnessed runoff out of a total of 200 weeks used in the study. Therefore, considering the limited number of runoff events as well as non-suitability of proper pdfs, we have neglected the hydrologic drought in our analysis. Considering that our focus is limited to the anatomy of a local-scale agricultural drought, we focused more on meteorological and agricultural drought indices. Using three statistical tests (Kolmogorov-Smirnov, AndersonDarling, and Chi-square test), the gamma distribution was selected for precipitation and normal distribution was selected for soil moisture to derive standardized drought indices for further analysis.

Results revealed that drought indices did not respond equally to a drought condition, which means different drought conditions are likely to be observed from surface and subsurface drought indices at the same time. The drought indices based on 1-week and 3-week temporal scale is plotted in Figure 7. It is observed that there are often mismatches between drought 
severities occurring during growing periods over different years. This suggests that even when there is a meteorological drought, there may not be an agricultural drought, and vice versa. This characteristic may likely be due to the small temporal resolution (i.e., weeks), since at such a resolution there may be a continuous feedback of soil moisture from the lower layer to the upper layer because of suction properties of root zones. The drought characteristics also vary along the soil layers. For example, in 2009, the drought based on SPI3 continued towards the end, whereas based on SSMI3_L1, the drought conditions improved and reached a normal condition because of the assimilation of RS soil moisture. Therefore, despite the fact that meteorological drought dominated during 2009, a satisfactory crop yield was obtained due to the moisture supply available in layer 1 of the soil profile.

The box plot of the drought severity considering all the drought indices at a 1-week temporal scale is shown in Figure 8. The drought events were selected at the zero threshold level to include near- normal to extreme drought conditions. It is observed that: (a) the mean of drought severity for SPI1 and SSMI_L1 remain nearly same, although higher range is observed for SSMI1_L1; (b) the mean of drought severity increases with depth from layer 1 to layer 2, and maximum mean was noticed for SSWI1; (c) the extreme meteorological drought that occurred during 2009 according to station rainfall data was also reflected for different soil layers as well as total soil water availability up to $180 \mathrm{~cm}$; and (d) a higher range was observed for soil layer 2 in comparison to layer 1 . These findings were also observed when the temporal scale was increased from 1 week to 3 weeks.

\subsection{Co-evolution of rainfall and drought indices}

The co-evolution between rainfall and drought indices was quantified using both cross correlation and wavelet analysis. The cross-correlation analysis between weekly rainfall and 
392 drought indices can provide their linear strength at different lag times, which can improve 393 agricultural water management by forecasting drought information at greater lead times. Some of 394 the findings highlighted the relationship between rainfall and drought indices; however, the 395 relationship was not evaluated for agricultural droughts considering soil moisture availability for 396 crop growth at subsurface scenarios. The cross-correlation plot between weekly rainfall and 397 drought indices of different temporal scales is shown in Figure 9. As expected, weekly rainfall 398 has comparatively higher correlation strength with its direct product SPI time series in the 399 sequence SPI1, SPI2, SPI3, and SPI4. However, the pattern changes for the soil moisture 400 droughts beneath the surface, with maximum correlation observed at a temporal scale of two 401 weeks. This suggests, using weekly rainfall, one can predict SSMI2_L1 and SSMI2_L2, and it 402 may be expected that the forecasting performance might decrease with the increase in depth. The 403 maximum correlation between weekly rainfall and drought indices were observed at different lag 404 times. For example, the lag time between weekly precipitation and SSMI3_L1 and SSMI4_L1 405 happens to be 2 and 3 weeks, respectively. The soil moisture available in different layers will be 406 used at different lag times for crop growth in case the meteorological drought creeps in at the 407 weekly timescale.

408 Wavelet analysis was carried out for weekly rainfall and drought indices at different temporal 409 scales. Based on weekly rainfall, the significant power was observed at 3 to 8 weeks during 410 2008, which happens to be a wet year (Figure 10a). Similar observations were also made when 411 weekly rainfall was translated to SPI1 and SPI2. However, additional significant power was 412 observed during 2003 (normal year) based on the SPI3 and SPI4 analysis. This suggests that the 413 significant power of meteorological drought signal could not be captured by the SPI time series, 414 based on a weekly temporal scale. However, significant power could possibly be captured at 
415 lower temporal scales (e.g., months). The subsurface drought indices could capture the drought 416 periods with significant powers. For example, using SSMI1_L1, the significant powers were 417 observed for both wet and dry years, whereas using coarser temporal resolution at 4 weeks 418 (SSMI4_L1), the significant powers were observed for all conditions: normal years (2003 to 419 2005) with significant power at 8-12 weeks, wet year (2008) at two significant powers (5-10 and 420 16-20 weeks), and drought year (2009) with significant power observed at 20-30 weeks (Figure 421 10b). The temporal scale length also plays an important role in capturing significant power, that 422 was observed in subsurface drought indices. The significant powers also differed when surface 423 and subsurface drought indices were compared.

424 The cross-spectral power was also investigated between weekly rainfall and drought indices to 425 evaluate their evolution over different time periods. The cross-wavelet analysis generates cross426 spectral power, which was calculated against a red noise background and indicated by plotting 427 black outline at the 5\% significant level (Figure 11). The cross-wavelet transform also detects 428 cross magnitude and significant periods. It was observed that all the surface and subsurface 429 drought indices evolved with weekly rainfall, however, their evolution varies with different crop 430 periods. For example, SPI evolves with weekly rainfall and significant powers scattered between 4311 and 9 weeks for different time periods, with more prominence during 2008 (Figure 11a). 432 Similarly, the weekly rainfall influences the subsurface drought indices, however, the difference 433 is observed with respect to surface drought. For example, the weekly rainfall acts differently on 434 the transition of drought from space to the top soil layer (i.e., transition from SPI1 to 435 SSMI1_L1), the cross wavelet properties change as significant powers in the range of 1-6 weeks 436 were no longer observed during 2003-2005 for SSMI1_L1 (Figure 11b). This means that the 437 weekly rainfall has high interactivity with SPI at comparatively shorter timescales in comparison 
to SSMI1_L1. The other additional observations of significant power at 32 weeks may not

439 provide useful information as our objective is to focus on crop periods at shorter time intervals.

440 These observations could significantly predict agricultural drought conditions by combining a

441 forecasting method with the cross wavelet information (Ozger et al., 2012 ).

$442 \quad 3.4$ Persistence properties of drought indices

443 The Hurst exponent (H) of SPI, SSMI_L1, SSMI_L2, SSMI_L3 and SSWI at different temporal 444 scales were calculated and compared (Figure 12). The value of $\mathrm{H}$ greater than 0.5 indicates that 445 the drought index time series is persistent, which are essentially black noise processes and often 446 occurs in nature (Mishra et al., 2009). It is noted that the persistence of precipitation-based SPI 447 series at a temporal resolution of 1 week is comparatively less than that at longer temporal scales 448 (2-4 weeks). Considering a 1-week temporal scale, higher persistence in soil moisture drought in 449 layer 1 is observed to be higher than SPI1; however, with increase in temporal scale to 4 weeks, 450 both the indices have similar persistent properties. Interestingly, the persistence of soil moisture 451 drought in layers 2 and 3 and total soil water availability do not change, based on their 452 aggregated temporal scale. This means that both shorter (1 week) and longer (4 week) temporal 453 scales will have similar persistence of drought progression and recession in bottom layer drought 454 indices (SSMI_L2, SSMI_L3 and STSWI). The persistence dynamics were mostly observed for 455 the SPI time series followed by the soil moisture drought in layer 1 (SSMI_L1).

456 3.5 Probabilistic analysis of surface and subsurface drought indices

457 Copulas were used to evaluate the probabilistic properties of surface and subsurface droughts. In 458 order to study the relationship between duration and severity of drought events, we first 459 examined the association between these two variables graphically through Kendall's plot (K460 plot) and chi-plots and then selected suitable copulas that capture the dependence structure 
461 between these variables for different time periods, and for precipitation, soil moisture across the

462 soil horizon, and total soil water. Data for the 2-week temporal resolution is used for illustration.

463 Dependence structure between drought duration and severity

464 Figure 13 shows the K-plots for SPI2 and SSMI2_L1. A K-plot is similar to a Q-Q plot with the 465 exception that data points falling on the diagonal line are deemed independent and points above

466 (below) the diagonal indicate positive (negative) dependence. As expected, we note a positive

467 dependence between duration and severity for precipitation, soil moisture, and total water

468 availability, i.e. as drought duration lengthens, the severity of the event also increases. A similar

469 behavior is noted also for SMI2_L2, SMI2_L3, and SSWI2 (not shown here).

470 Chi-plots allow a visual assessment of the dependence structure of the whole dataset and the

471 upper and lower tails separately. Chi-plots are based on the chi-square statistics for independence

472 in a two-way table. In the case of independence, the data point will fall within the two control

473 lines. Lower (upper) tail values are those that are smaller (larger) than the mean. The first

474 column of Figure 14 shows the chi-plots for the whole dataset, and the second and third columns

475 show the lower and upper tails, respectively. Significant positive association can be noted

476 between duration and severity. The dependence appears slightly stronger in the upper tail than in

477 the lower tail. This is particularly the case for precipitation and soil moisture in soil layer 1,

478 which implies that longer drought events have more severe impacts. The behavior of 479 precipitation and soil moisture in soil layer 1 is very similar, an indication that the topmost layer 480 responds to changes in the atmospheric conditions.

$481 \quad$ Modeling and simulation of duration and severity

482 Copula permits modeling of the dependence between duration and severity, even though the 483 marginals do not belong to the same family of distributions; for example, the duration of drought 
484 events for SPI2 follows the Frechet distribution, while severity follows a lognormal distribution.

485 Copula parameters were estimated using the maximum pseudo-likelihood method from the 486 following suite of copulas: Elliptical family (Gaussian and Student's t), Archimedean (Clayton, 487 Gumbel, Frank, Joe, BB 1, BB 6, BB 7, and BB 8). The BB copulas are from the two-parameter 488 families, which can capture different degrees of dependence between the variables in the body or 489 at the tails.

490 In order to study the relationship between duration and severity of drought events, we first 491 examine the association between these two variables graphically through Kendall's plot (K-plot) 492 and chi-plots and then select suitable copulas that capture the dependence structure between 493 these variables for different time periods, and for precipitation, soil moisture across the soil 494 horizon, and total soil water. A combination of graphical and analytical methods (Akaike 495 Information Criteria) were used for the copula selection. Data for 2-week average is used for 496 illustration. The most suitable copula that deemed to capture the dependence between drought 497 duration and severity varies both across timescales and depths (Table 2). For a temporal scale of 4982 weeks, the dependence structure for precipitation and soil moisture in the first layer can be 499 modeled via the Joe copula, and the Gaussian and Frank copulas are deemed most appropriate 500 for layer 2 and 3, respectively. Figure 15 allows a visual comparison of observed data 501 superimposed over randomly generated values from the chosen copula for SPI2 (Fig. 15(a)) and 502 SSMI2_L2 (Fig. 15(b)).

503 Averaging over timescale (i.e. going from 1 week to 4 weeks), we note that the Joe copula is the 504 preferred copula for precipitation for 1-week and 2-week scales, while the Gumbel copula is 505 better suited to model the dependence structure for 3-week and 4-week scales. Both the Joe and 506 Gumbel copulas exhibit upper tail dependence. Note that such upper tail dependence is due to the 
507 508

one extreme event (duration of 23 weeks and associated severity of 34.6 for SPI2 and duration of 20 weeks and severity of 22.5 for SSMI2_L2), that dictates the behavior of the upper tail and guides the choice of copula. The presence of this one extreme event is interesting, as it suggests that the occurrence of extremely severe long duration drought is not impossible, and thus events with intermediate characteristics is not improbable. It is also important to note that when averaging over longer time scales, the tail behavior becomes less dominant.

Moving from the topmost soil layer to the lower layers, we note that the choice of copula again changes. The topmost layer exhibits upper tail dependence, as it responds faster to the changes in atmospheric conditions; that is, lack of rainfall quickly leads to soil moisture deficit and as the drought lingers, it leads to the depletion of moisture in the topmost soil layer. The subsurface layers respond slower to drought events. Often, even before any depletion of soil moisture starts, the upper layer drought has ended. In fact, such tail behavior, as demonstrated via the K-plots and chi-plots, is present in the upper tail in the precipitation and upper soil moisture data and slowly disappears with depth. This behavior is further visible in the choice of copula. The copula deemed suitable for the subsurface layers are the ones that do not exhibit strong upper tail dependence (e.g. Gaussian and Frank).

\subsection{Impact of drought on maize yields}

Here we present the impact of drought severity, duration, maximum severity, maximum duration and number of events only to aggregated maize yields at different temporal scales. The scatter plot and correlation coefficient were used to evaluate the causal effect of drought properties on aggregated maize yields. It is interesting to note that drought severity does not have a strong signal to the $5^{\text {th }}$ percentile yields from the $1^{\text {st }}$ and $2^{\text {nd }}$ soil layer soil moisture (SSMI_L1, SSMI_L2), although a negative slope was observed from the drought-yield relationship at 
530 different temporal scales, suggesting that the higher the severity the lower the yield that can be

531 achieved at the $5^{\text {th }}$ precentile category (Figure 16). However, soil moisture drought severity in

532 the $3^{\text {rd }}$ soil layer (SSMI_L3) at coarser temporal scales (i.e., 2, 3 and 4 weeks) has a significant

533 impact on the $5^{\text {th }}$ percentile yields, which is consistent with the analysis of Mishra et al. (2013) in

534 regards to the timing of water stress and yield relationship. More importantly, the drought

535 severity index for the total available water (SSWI) exercised the greatest impact on the $5^{\text {th }}$

536 percentile yields at different temporal scales. This suggests that of the four agricultural drought

537 parameters studied, the total profile soil moisture is the best indicator of the level of yields at

538 least at the $5^{\text {th }}$ percentile based on the severity of drought. Likewise, it is important to note that

539 the temporal scale of drought severity can also compound the analysis, as for the 3 -week

540 timescale, for example, lower correlation coefficient showed lesser sensitivity compared to the 1-

$541,2-$, and 4-week scales with the 2-week timescale having the strongest effect, again highlighting

542 the non-linearity of crop response to water stress, if a drought event occurred at the non-sensitive

543 period of crop growth the impact to crop yield is less severe as to when the drought occurred at

544 the sensitive period of crop growth.

As expected, the drought duration index for the total profile soil moisture (SSWI) gave

546 the strongest signal to impact the $5^{\text {th }}$ percentile yields (Figure 17). At the 3 -week timescale, this

547 signal was dampened compared to the 1-, 2-, and 4-week scales, again suggesting the non-

548 linearity in drought-yield response. The signal strength for the $3^{\text {rd }}$ soil layer soil moisture

549 (SSMI_L3) actually vanished compared to drought severity. The duration of drought posed to

550 have more direct effect on the $5^{\text {th }}$ percentile yields from the $1^{\text {st }}$ soil layer soil moisture

551 (SSMI_L1) at timescales of 1, 2, and 3 weeks, with the last one posing the strongest signal. This 
552 suggests that long duration droughts can deplete heavily the surface soil moisture and its signal

553 could be felt by the crops as this the most active layer for crop consumptive water use.

The maximum severity index further confirms the effectiveness of the SSWI as the best

555 index for agricultural drought (Figure 18). The strength is exceptional with $r$ ranging from 0.86

556 to 0.94 , with the strength highest for the 1 -week timescale, followed by 2 and 3 weeks. The

557 SSMI_L3 also retained the significant signal in regards to the maximum severity and $5^{\text {th }}$

558 percentile yield relationship, while SSMI_L1 and SSMI_L2 were not significant, although

559 posing negative slopes as well. As regards the maximum duration index, SSWI showed the most

560 significant signal (Figure 19). In the case of the SSMI_L3, higher correlation coefficient was

561 observed in comparison to other temporal scale. The strengths for SSMI_L1 for timescales of 2-

5624 weeks show some significant signal strengths as well. With respect to the relationship between

563 the number of events and $5^{\text {th }}$ percentile yields, we found that except for SSWI at the 3- and 4-

564 week timescales, there were no significant negative relationships observed (not shown). For the

$56550^{\text {th }}$ and $95^{\text {th }}$ percentile yields, there were no significant negative relationships found among the 566 drought indices examined at different temporal scales, although some negative slope was

567 determined at a higher time scale (not shown).

\section{Conclusions}

569 Among different types of droughts, agricultural drought seems to be the most complex, as it is 570 driven by both surface (i.e., evapotranspiration) and subsurface hydroclimatic fluxes (i.e., soil 571 moisture) at a local scale. Therefore, improving our understanding of the evolution of 572 agricultural drought is necessary to develop measures to reduce the impact of drought on food 573 security. This study utilizes the assimilated AMSR-E soil moisture and MODIS-LAI data in a 
574 crop model to investigate the anatomy of a local scale drought using surface and subsurface

575 hydrologic fluxes. The following conclusions are drawn from this study:

576 a) Agricultural drought differs from one crop to another. Understanding the anatomy of an 577 agricultural drought will remain a challenge due to our limited understanding of moisture 578 demand and supply for crop growth. The moisture demand is influenced by several 579 factors, and not limited to crop type, climate pattern, growing period, and their resilience 580 research community due to the difference in root zone depth between crops and nonuniform moisture supply from different soil layers. Agricultural drought monitoring should be driven by the root depth instead of a fixed depth.

b) Assimilation of soil moisture and leaf area index into crop modeling framework might be more suitable for agricultural drought quantification, as it performs better in simulating crop yield. This assimilation scheme is also able to capture better information between weekly precipitation and subsurface soil moisture in different layers and scale processes.

c) Surface and subsurface drought indices do not respond equally to a similar drought condition at shorter temporal resolutions (e.g., weeks), which suggests different drought conditions are likely to be observed from surface and subsurface drought indices at the same time. This information is critical in evaluating the soil moisture available in different soil layers for crop growth during drought periods.

d) The persistence of subsurface droughts is in general higher than surface droughts. The dynamics in persistence were observed in SPI and soil moisture drought at 0 to $5 \mathrm{~cm}$ soil thickness. The soil moisture drought in layers 2 and 3 and total soil water availability do not change, based on their aggregated temporal scale. 
e) Positive association between duration and severity was observed in surface and subsurface drought events at all timescales. The dependence is slightly stronger at the upper tail. The dependence structure, especially the presence of one long-duration highseverity event, determines the choice of copula. This extreme event is more pronounced in precipitation and the top soil layer but is dampened in lower layers.

f) It is found that the total water available in the soil profile is the best parameter for describing the agricultural drought in the study region. However, it changes with crops (short vs. longer root zone), climatic zones, and type of soil to retain soil moisture in different layers.

Acknowledgement: We acknowledge the supports of CCAFS, NASA/JPL SERVIR project, NASA SMAP Early Adopter and NOAA Cooperative Grant \#NA05OAR4311004 in developing the crop model-data assimilation system. We thank two anonymous reviewers for their positive and constructive comments on an earlier version of this manuscript.

\section{References:}

Bhalme, H.N., Mooley, D.A., 1980. Large-scale droughts/floods and monsoon circulation. Mon. Weather Rev. 108, 1197-1211.

Bruce, J.P., 1994. Natural disaster reduction and global change. Bull. Am. Meteorol. Soc. 75, $1831-1835$.

Chowdhary, H., Escobar, L. and Singh, V., 2011. Identification of suitable copulas for bivariate frequency analysis of flood peak and flood volume data. Hydrology Research, 42(2-3): $193-216$.

Dai, A. 2010. Drought under global warming: a review. Wiley Interdisc. Rev. Clim. Change 2, 45-65.

de Wit, A. J. W. \& Van Diepen, C.A. (2007). Crop model data assimilation with the Ensemble Kalman filter for improving regional crop yield forecasts. Agricultural Forest Meteorology, 146, 38-56. 
Doorenbos, J. \& Kassam, A.H. (1979). Yield response to water. FAO Irrigation and Drainage Paper No. 33. Rome, FAO.

FAO; Crop water needs, Chapter 3, http://www.fao.org/docrep/s2022e/s2022e07.htm (Date accessed 25th June 2014).

Genest, C. and Favre, A.-C., 2007. Everything You Always Wanted to Know about Copula Modeling but Were Afraid to Ask. Journal of Hydrologic Engineering, 12(4): 347-368.

Hao, Z., and AghaKouchak, A. 2014. A Nonparametric Multivariate Multi-Index Drought Monitoring Framework. J. Hydrometeor, 15, 89-101.

Heim, R., 2002. A review of twentieth-century drought indices used in the United States. Bull. Am. Meteorol. Soc. 83, 1149-1165.

Hollinger, S.E., Isard, S.A., Welford, M.R., 1993. A New Soil Moisture Drought Index for Predicting Crop Yields. In: Preprints, Eighth Conf. on Applied Climatology, Anaheim, CA, Amer. Meteor. Soc., pp. 187-190.

Houborg, R., M.Rodell, B.Li, R.Reichle, and B. F.Zaitchik (2012), Drought indicators based on model-assimilated Gravity Recovery and Climate Experiment (GRACE) terrestrial water storage observations, Water Resour. Res., 48, W0752.

Ines, A.V.M., Das, N.N., Hansen, J.W. \& Njoku, E.G. (2013). Assimilation of remotely sensed soil moisture and vegetation with a crop simulation model for maize yield prediction. Remote Sensing of Environment. 138: 149-164. doi: 10.1016/j.rse.2013.07.018.

IPCC, 2013: Summary for Policymakers. In: Climate Change 2013: The Physical Science Basis. Contribution of Working Group I to the Fifth Assessment Report of the Intergovernmental Panel on Climate Change [Stocker, T.F., D. Qin, G.-K. Plattner, M. Tignor, S.K. Allen, J. Boschung, A. Nauels, Y. Xia, V. Bex and P.M. Midgley (eds.)]. Cambridge University Press, Cambridge, United Kingdom and New York, NY, USA.

Jones, J.W., Hoogenboom, G, Porter, C., Boote, K. J., Batchelor, W. D., Hunt, L. A., Wilkens, P. W., Singh, U., Gijsman, A. J. \& Ritchie, J.T. (2003). The DSSAT Cropping System Model. European Journal of Agronomy, 18, 235-265.

Khedun, C.P., Chowdhary, H., Mishra, A.K., Giardino, J.R. and Singh, V.P., 2013. Water Deficit Duration and Severity Analysis Based on Runoff Derived from the Noah Land Surface Model. Journal of Hydrologic Engineering. 18(7), 817-833. 
Khedun, C.P., Mishra, A.K., Singh, V.P. and Giardino, J.R., 2014. A Copula-Based Precipitation Forecasting Model: Investigating the Effect of Interdecadal Modulation of ENSO's Impacts on Monthly Precipitation. Water Resources Research, 50, 580-600, doi:10.1002/2013WR013763.

Kogan, F.N., 1997. Global drought watch from space. Bull. Am. Meteorol. Soc. 78, 621-636.

Kranz, William L., Suat Irmak, Simon van Donk, C. Dean Yonts, and Derrel L. Martin. 2008. Irrigation Management for Corn. NebGuide G1850. UNL Extension Division. 4 pp.

Li, B., et al. (2012), Assimilation of GRACE terrestrial water storage into a land surface model: Evaluation and potential value for drought monitoring in western and central Europe, J. Hydrol., 446-447, 103-115.

Liu, W.T., Kogan, F.N., 1996. Monitoring regional drought using the vegetation condition index. Int. J. Remote Sens. 17, 2761-2782.

Madadgar, S. and Moradkhani, H. 2013. Drought Analysis under Climate Change Using Copula. J. Hydrol. Eng.,18(7), 746-759.

McKee, T.B., Doesken, N.J., Kleist, J., 1993. The Relationship of Drought Frequency and Duration to Time Scales, Paper Presented at 8th Conference on Applied Climatology. American Meteorological Society, Anaheim, CA.

Mishra, A. K., and Singh, V. P. (2009). Analysis of drought severity-area-frequency curves using a general circulation model and scenario uncertainty. Journal of Geophysical ResearchAtmosphere, 114, D06120.

Mishra, A. K., Özger, M., and Singh, V. P. (2009). Trend and persistence of precipitation under climate change scenarios. Hydrological processes, 23(16), 2345-2357.

Mishra, A. K., and Singh, V. P. (2010). A review of drought concepts. Journal of Hydrology, 391(1-2), 202-216.

Mishra, A. and Coulibaly, P. (2014). Variability in Canadian Seasonal Streamflow Information and Its Implication for Hydrometric Network Design.J. Hydrol. Eng., 19(8), 05014003.

Mishra, A.K., Ines, A.V.M., Singh, V.P. \& Hansen. J.W. (2013). Extraction of information contents from downscaled precipitation variables for crop simulations. Stochastic Environmental Research and Risk Assessment. 27: 449-457. doi: 10.1007/s00477-0120667-9. 
Njoku, E. G., Jackson, T. L., Lakshmi, V., Chan, T. \& Nghiem, S.V. (2003). Soil Moisture Retrieval from AMSR-E. IEEE Transactions of Geosciences and Remote Sensing, 41, 215-229.

Obasi, G.O.P., 1994. WMO's role in the international decade for natural disaster reduction. Bull. Am. Meteorol. Soc. 75 (9), 1655-1661.

Ozger, M., Mishra, A. K., and Singh, V. P. (2012). Long lead time drought forecasting using a wavelet and fuzzy logic combination model: a case study in Texas. Journal of Hydrometeorology, 13, 284-297.

Palmer, W.C., 1965. Meteorologic Drought. US Department of Commerce, Weather Bureau, Research Paper No. 45, p. 58.

Palmer, W.C., 1968. Keeping track of crop moisture conditions, nationwide: the new crop moisture index. Weatherwise 21, 156-161.

Rajsekhar, D., Singh, V. P., Mishra, A. K. 2014. Hydrologic drought atlas for Texas, Journal of Hydrologic Engineering, (Accepted).

Rajsekhar, D., Singh, V.P. and Mishra, A.K., 2012. Hydrological Drought Atlas for the State of Texas for Durations from 3 Months to 36 Months and Return Periods from 5 Years to 100 Years Department of Biological and Agricultural Engineering, Texas A\&M University, College Station, Tx.

Shafer, B.A., Dezman, L.E., 1982. Development of a Surface Water Supply Index (SWSI) to Assess the Severity of Drought Conditions in Snowpack Runoff Areas. In: Preprints, Western SnowConf., Reno, NV, Colorado State University, pp. 164-175.

Sheffield, J. \& Wood, E. F. (2007). Characteristics of global and regional drought, 1950-2000: analysis of soil moisture data from off-line simulation of the terrestrial hydrologic cycle. J. Geophys. Res. 112, D17115.

Shiau, J.T. and Modarres, R., 2009. Copula-based drought severity-duration-frequency analysis in Iran. Meteorological Applications, 16(4): 481-489.

Singh, V. P., Khedun, C. P. and Mishra, A. K. 2014. Water, Environment, Energy, and Population Growth: Implications for Water Sustainability under Climate Change. J. Hydrol. Eng., 19(4), 667-673.

Singh, V.P. The use of entropy in hydrology and water resources. Hydrol. Process. 1997, 11, $587-626$. 
Sklar, A., 1959. Fonctions de repartition à $\mathrm{n}$ dimensions et leurs marges. Publications de l'Institut de Statistique de l'Université de Paris, 8: 229-231.

Steduto, P., Hsiao, T.C. Fereres, E. \& Raes, D. (2012). Crop yield response to water. FAO Irrigation and Drainage Paper No. 33. Rome, FAO.

Svoboda, Mark, and Coauthors, 2002: The Drought Monitor. Bull. Amer. Meteor. Soc., 83, $1181-1190$.

Tallaksen, L. M., Hisdal, H., and van Lanen, H. A. J.: Space-time modelling of catchment scale drought characteristics, J. Hydrol., 375, 363-372, 2009.

Van Lanen, H. A. J., Wanders, N., Tallaksen, L. M., and Van Loon, A. F. 2013. Hydrological drought across the world: impact of climate and physical catchment structure, Hydrol. Earth Syst. Sci., 17, 1715-1732, doi:10.5194/hess-17-1715-2013.

Van Loon, A. F., E. Tijdeman, N. Wanders, H. A. J. Van Lanen, A. J. Teuling, and R. Uijlenhoet (2014), How climate seasonality modifies drought duration and deficit, J. Geophys. Res. Atmos., 119, 4640-4656.

Vazifedoust, M., Van Dam, J. C., Bastiaanssen, W. G. M. \& Feddes, R.A. (2009). Assimilation of satellite data into agrohydrological models to improve crop yield forecasts. International Journal of Remote Sensing, 30, 2523-2545.

Vicente-Serrano, Sergio M., Santiago Beguería, Juan I. López-Moreno, 2010: A Multiscalar Drought Index Sensitive to Global Warming: The Standardized Precipitation Evapotranspiration Index. J. Climate, 23, 1696-1718.

Wang, D., M. Hejazi, X. Cai, A. J. Valocchi, 2011. Climate change impact on meteorological, agricultural, and hydrological drought in central Illinois, Water Resour. Res., 47, W09527,

Wada, Y., van Beek, L. P. H., Wanders, N., and Bierkens, M. F. P. 2013. Human water consumption intensifies hydrological drought worldwide, Environ. Res. Lett., 8, 034036, doi:10.1088/1748-9326/8/3/034036.

Whitaker, J. S. \& Hamill, T. M. (2002). Ensemble data assimilation without perturbed observations. Monthly Weather Review, 130, 1913-1924.

Zhang, L. and Singh, V.P., 2007. Trivariate Flood Frequency Analysis Using the GumbelHougaard Copula. Journal of Hydrologic Engineering, 12(4): 431-439. 
747 Qiang Zhang, Peng Sun, Jianfeng Li, Vijay P. Singh, Jianyu Liu, 2014. Spatiotemporal 748 749 properties of droughts and related impacts on agriculture in Xinjiang, China. International Journal of Climatology, DOI: 10.1002/joc.4052.

750 Qiang Zhang, Vijay P. Singh, Mingzhong Xiao, Jianfeng Li, 2012. Regionalization and spatial 751 changing properties of droughts across the Pearl River basin, China. Journal 752 of Hydrology, 472-473, 355-366.

753

754

755

756

757

758

759

760

761

762

763

764

765

766

767

768

769

770

771

772 
Anatomy of a local-Scale Drought: Application of Assimilated Remote Sensing Products,

776

777

778

Figures

779

780

781

782

783

784

785

786

787

788

789

790

791

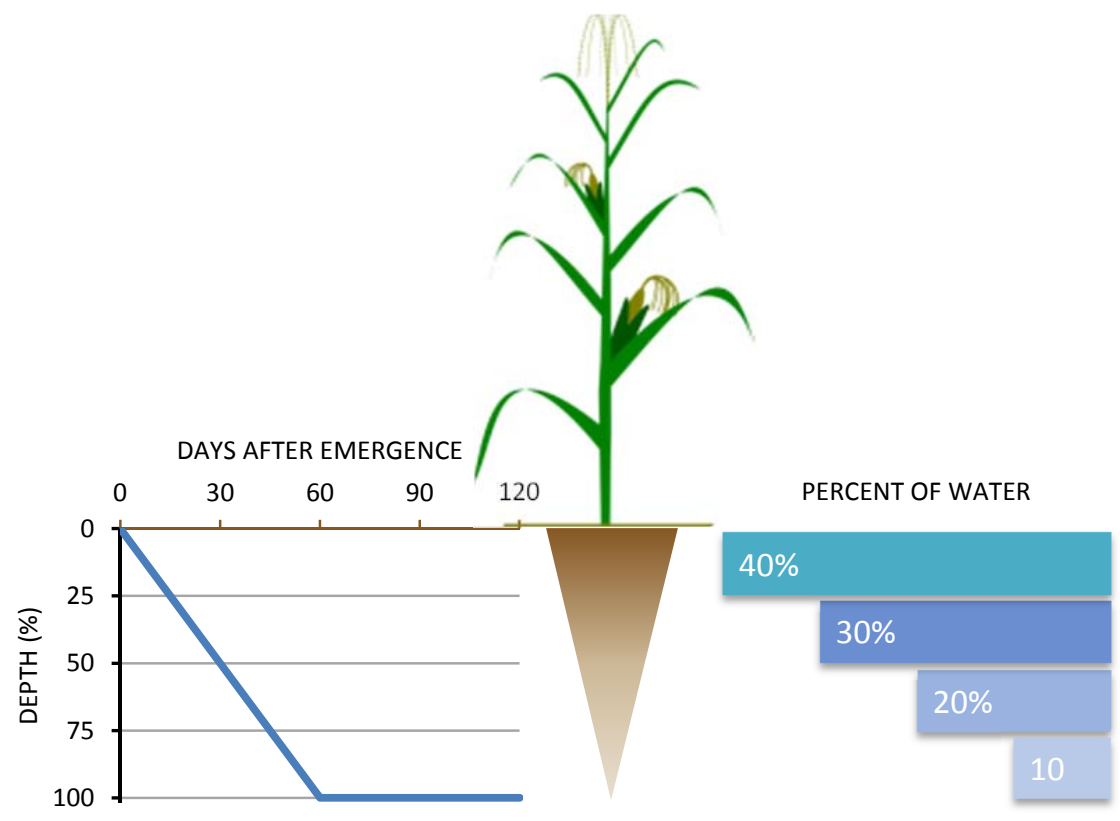

792

793

794

Figure 1. Variation of soil water extraction by Corn with respect to depth and plant root 795 development patterns (Kranz et al., 2008).

796

797

798 
Crop model - Data Assimilation Framework (Figure 2b)

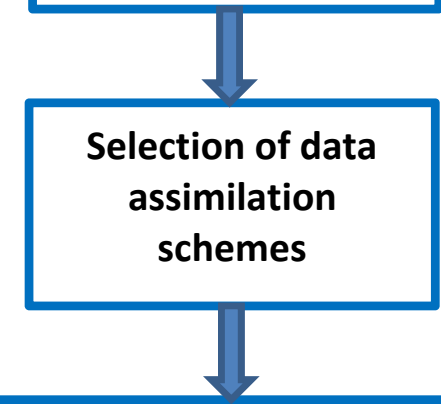

Statistical Models Correlation analysis, Entropy, Copula, Wavelet, Hurst exponent

and

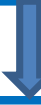

Drought related outputs

Co-evolution of rainfall and drought indices Persistence properties of drought indices Probabilistic analysis of drought indices Impact of drought on crop yields 
Figure 2a. Framework for local scale drought study using combination of models.

826

827

828

829

830

831

832

833

834

835

836

837

838 


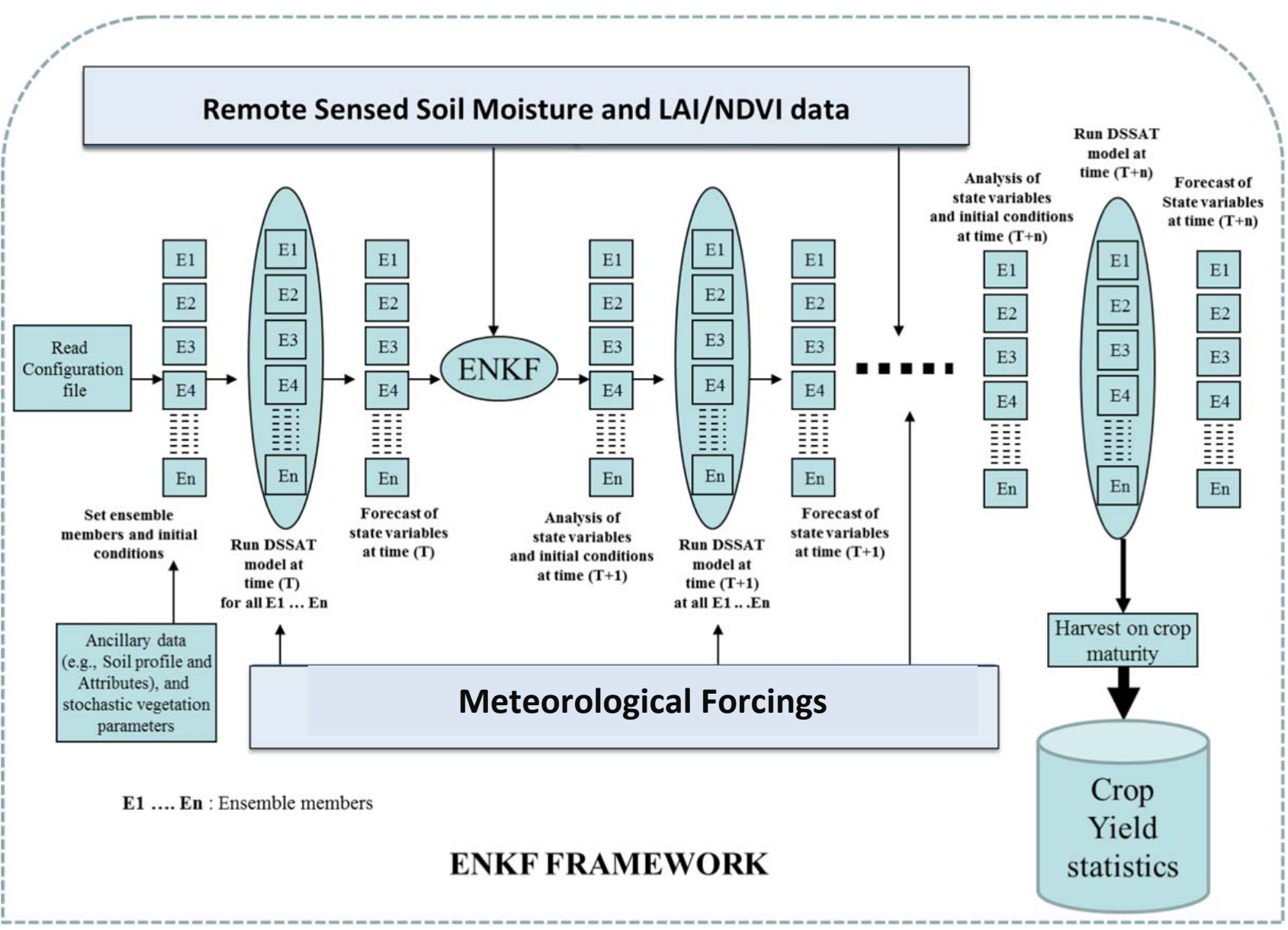

Figure 2b. Crop model-data assimilation framework (Ines et al. 2013). 


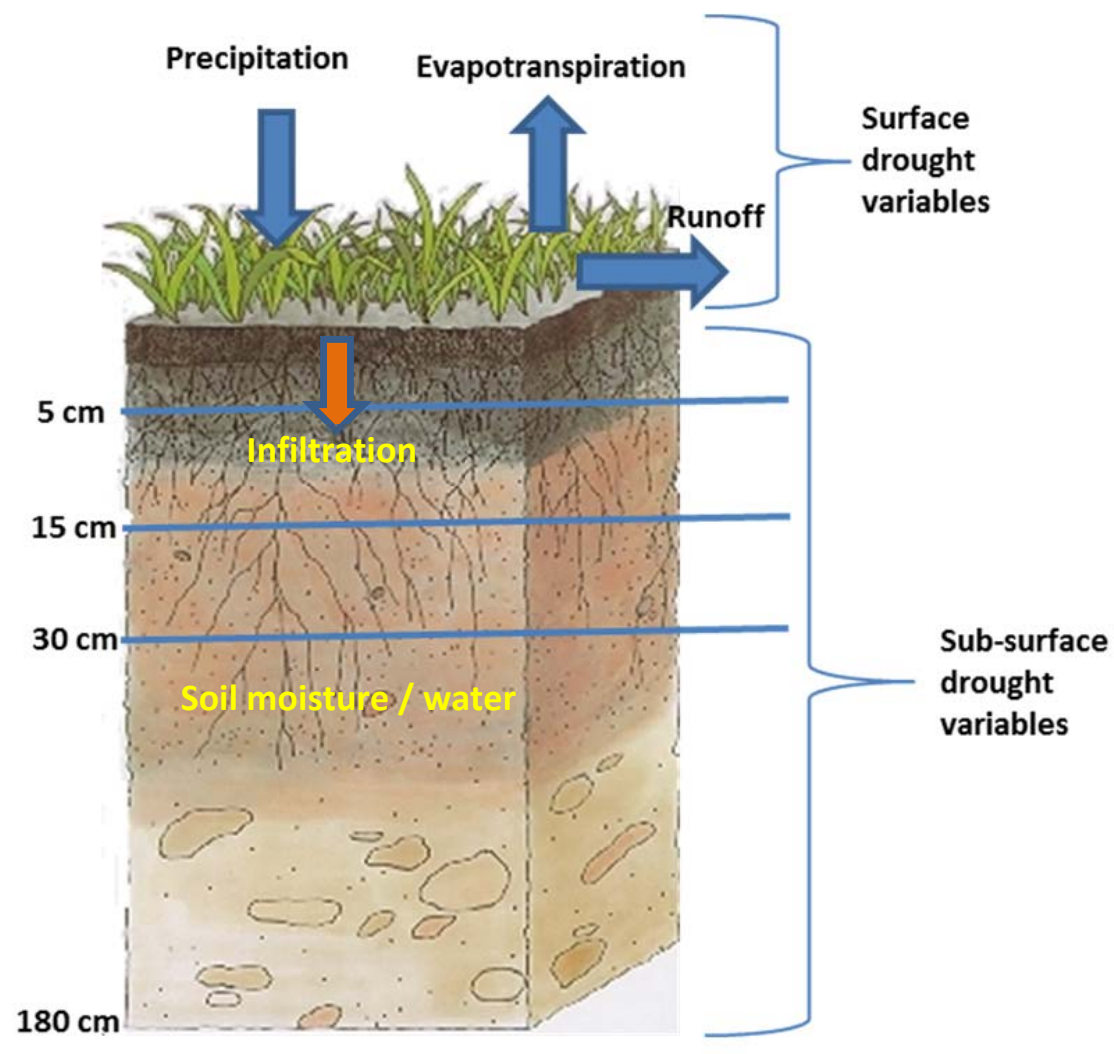

Figure 3. Distinction between surface and subsurface drought variables

854

855

856

857

858

859

860

861

862

863

864 


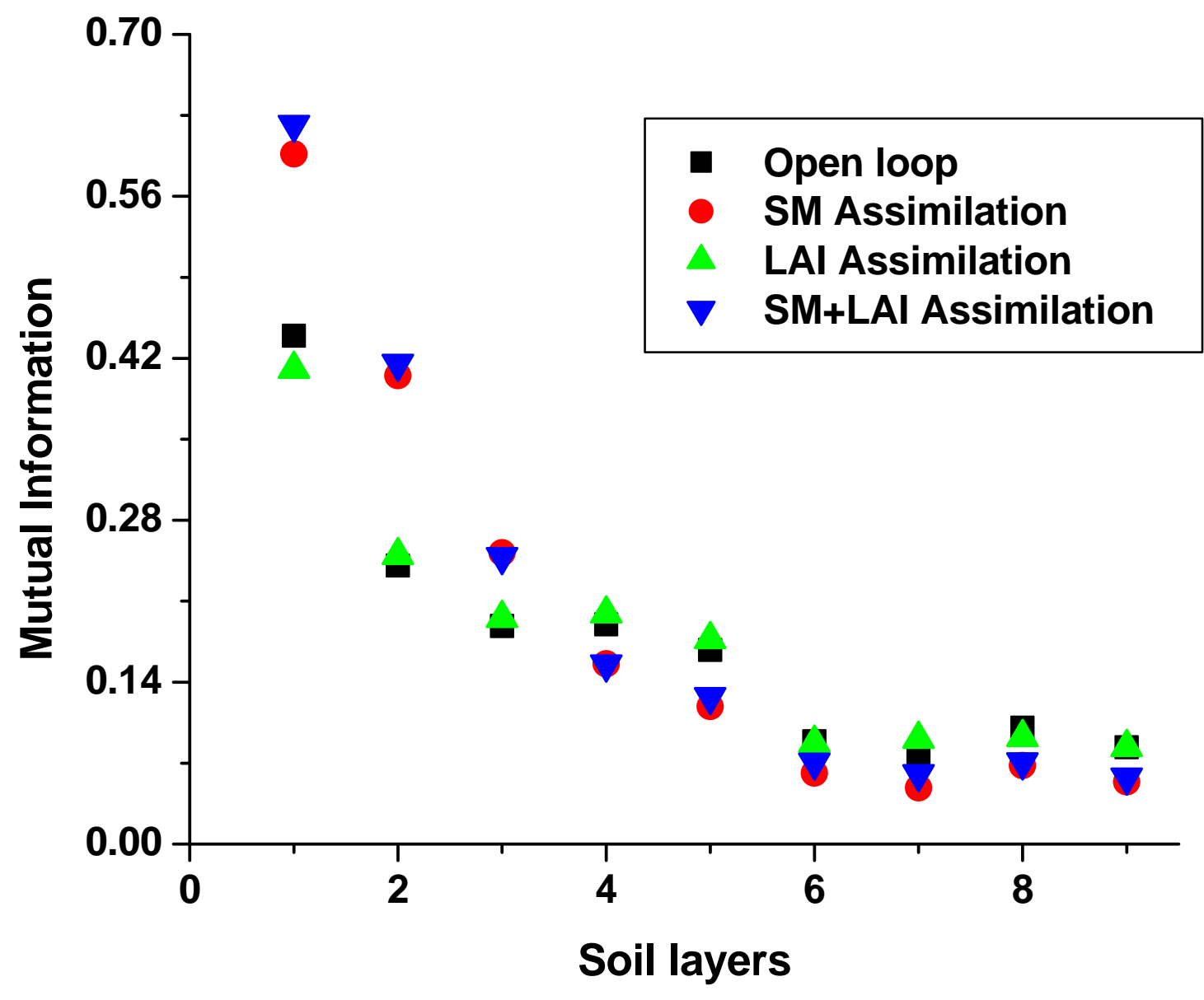

870 Figure 4. Mutual information between weekly rainfall and soil moisture at different layers based 871 on different assimilation schemes.

872

873

874

875

876

877 
883

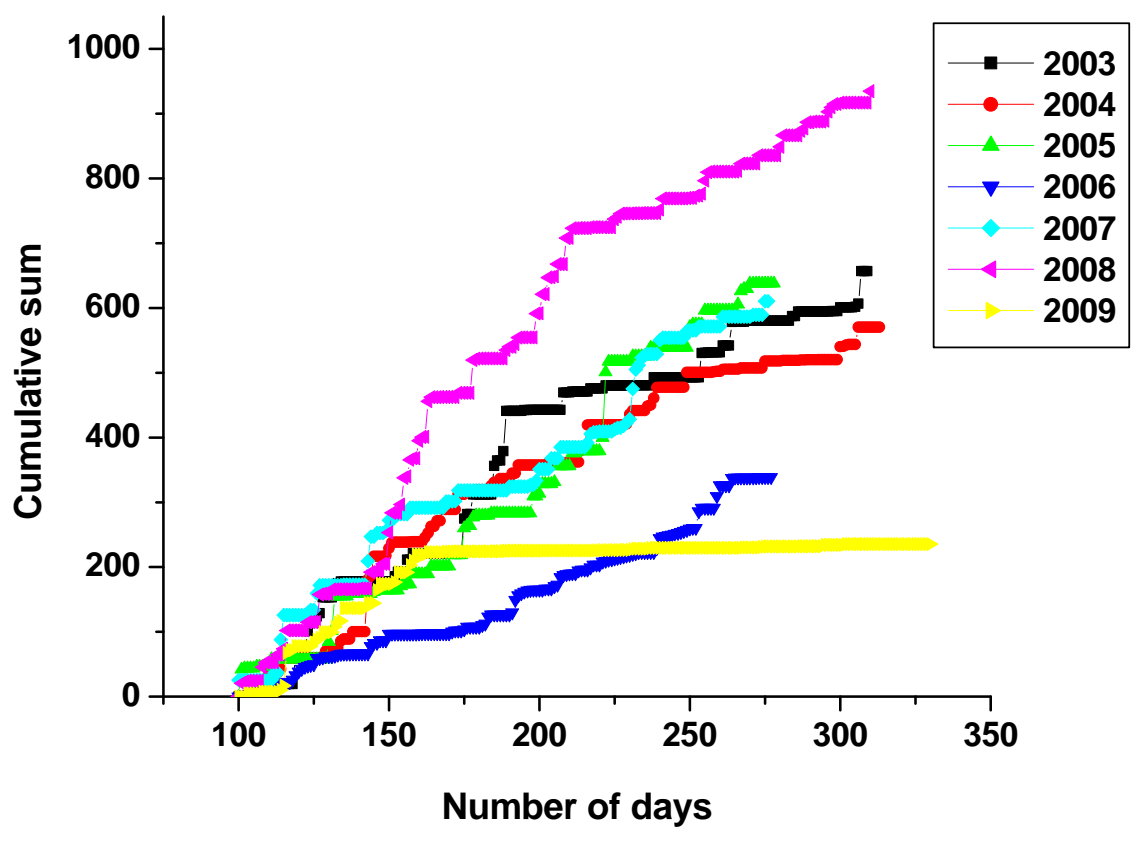

Figure 5. Cumulative precipitation pattern during crop periods for different years. 
901

902

903

904

905

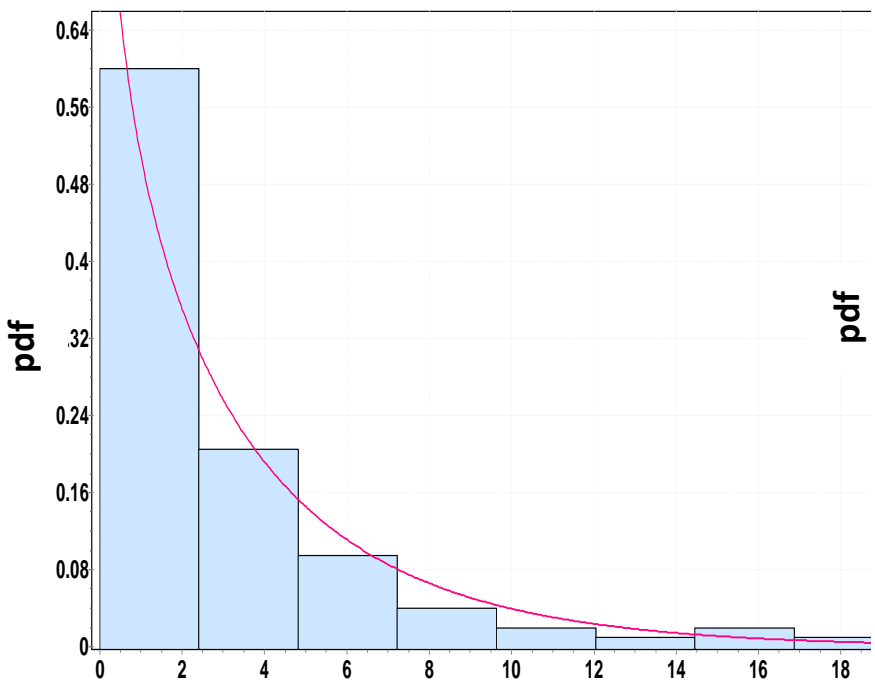

(a) Rainfall

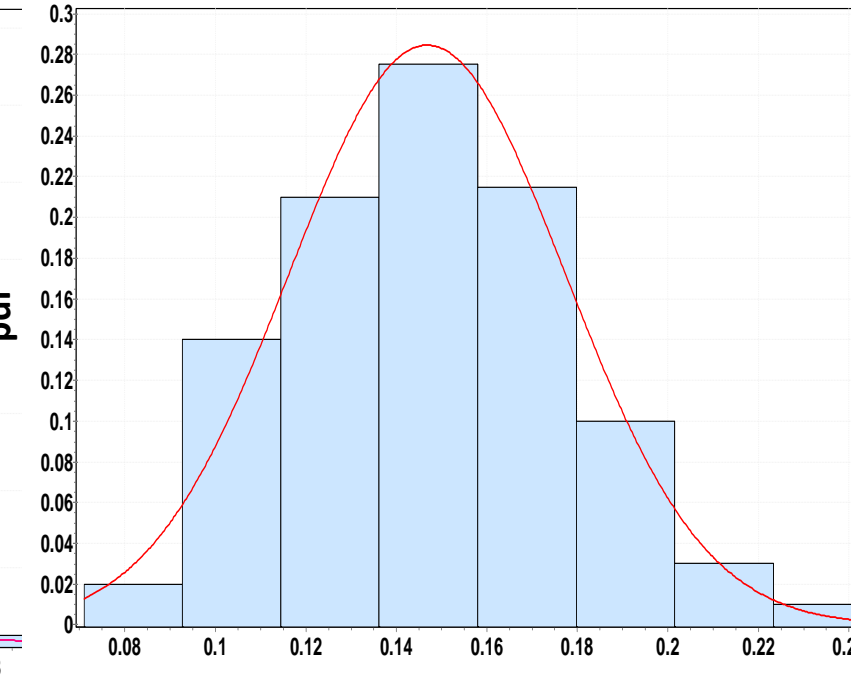

(b) Soil moisture (layer 1)

906

Figure 6. Probability density function of weekly rainfall and soil moisture (layer 1)

908

909

910

911 


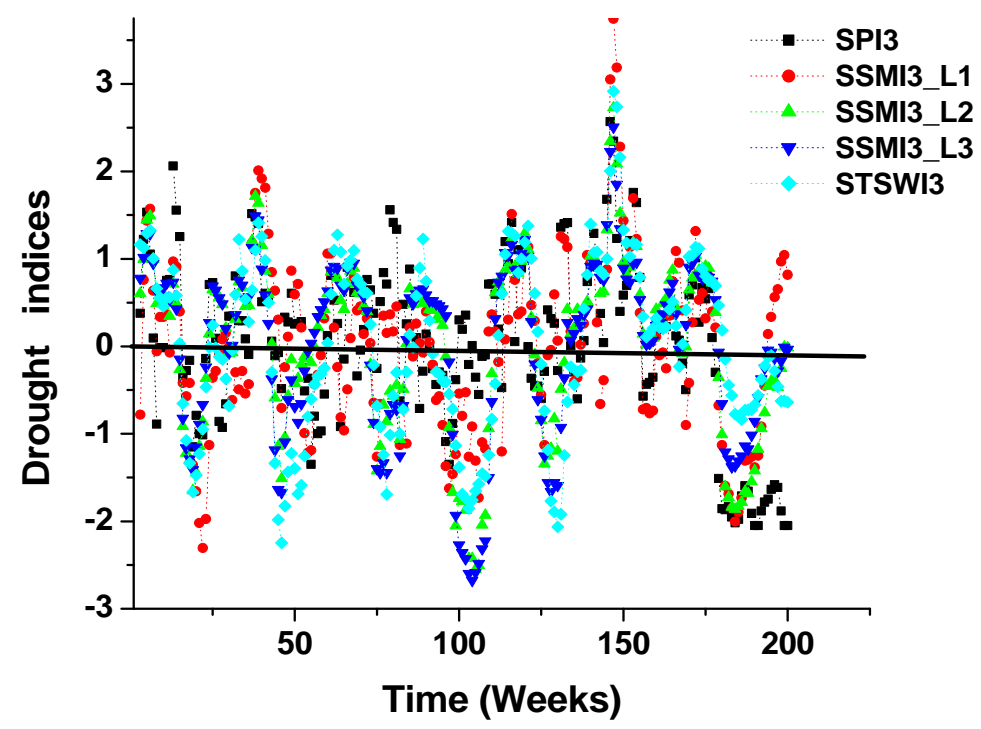

(b) Temporal scale 3 weeks

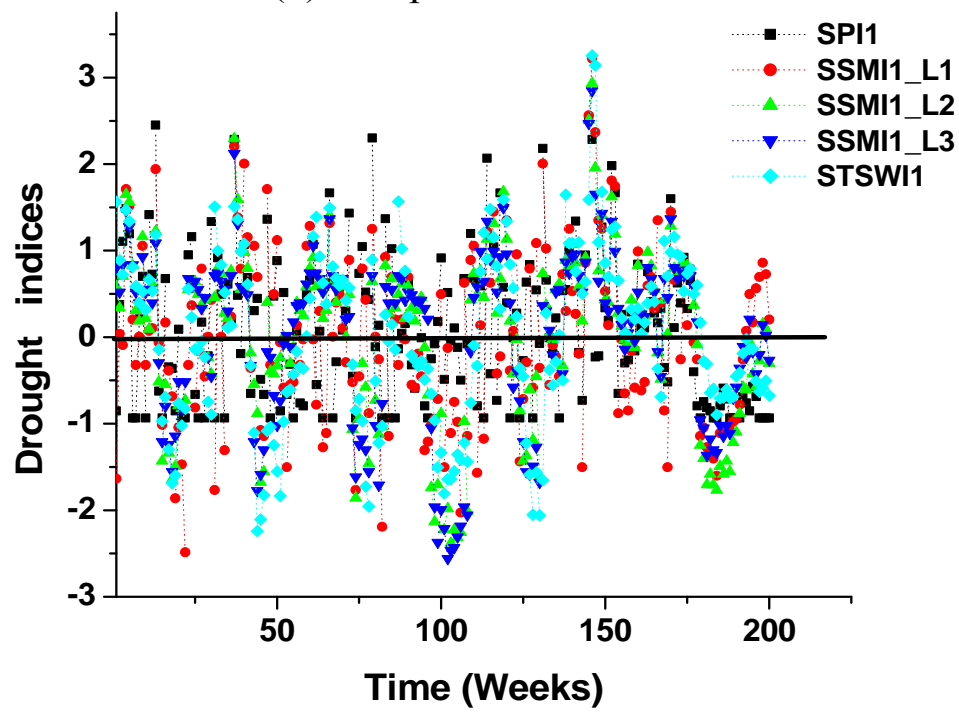


(a) Temporal scale 1 week

920 Figure 7. Time series plot of different drought indices during crop period for 2003-2009. [Note 921 that $\mathrm{x}$-axis represents duration of crop periods for different years: 2003 (1-30 weeks), 2004 (31-

92261 weeks), 2005 (62-87 weeks), 2006 (88-112 weeks), 2007 (113-137 weeks), 2008 (138-167 923 weeks), and 2009 (168-200 weeks)].

924

925

926

927

928

929

930

931

932

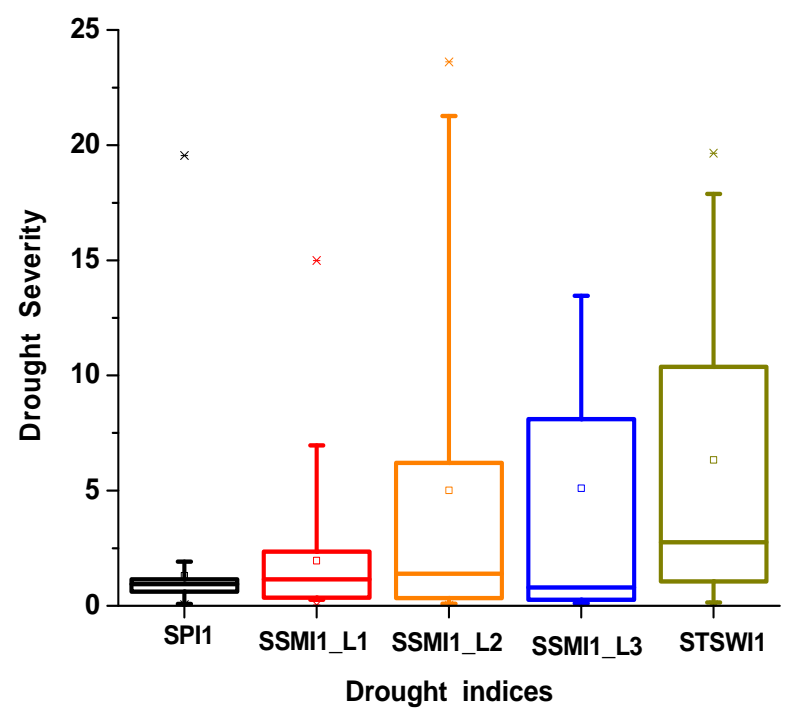

Figure 8. Box plot of the drought severity of drought indices at 1 week temporal scale. 
938

939

940

941

942

943

944

945

946

947

948

949

950

951

952

953

954

955 


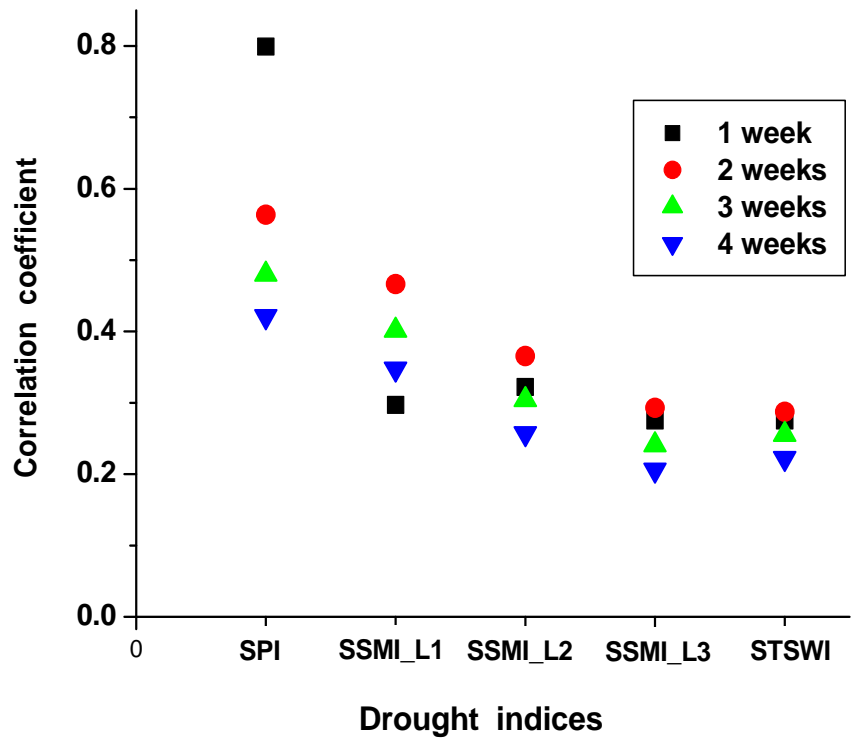

957 Figure 9. Cross correlation plot between weekly rainfall and drought indices of different 958 temporal scales.

959

960

961

962

963

964

965

966

967

968

969

970

971

972

973 


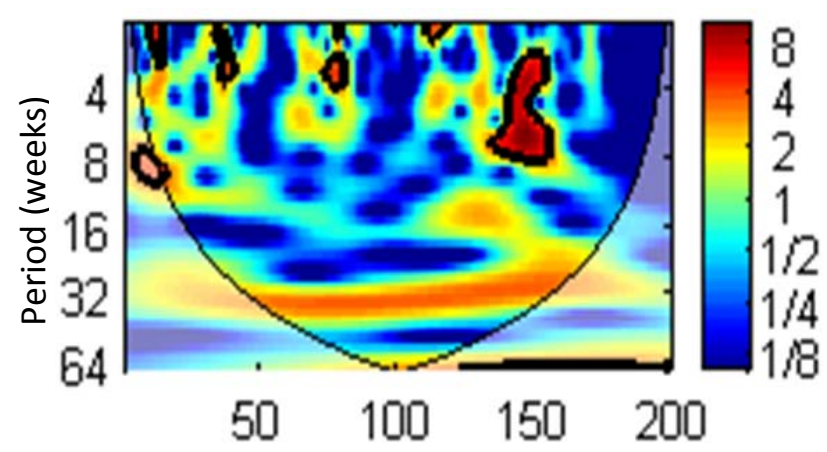

Time scale (weeks)

(a) Weekly rainfall

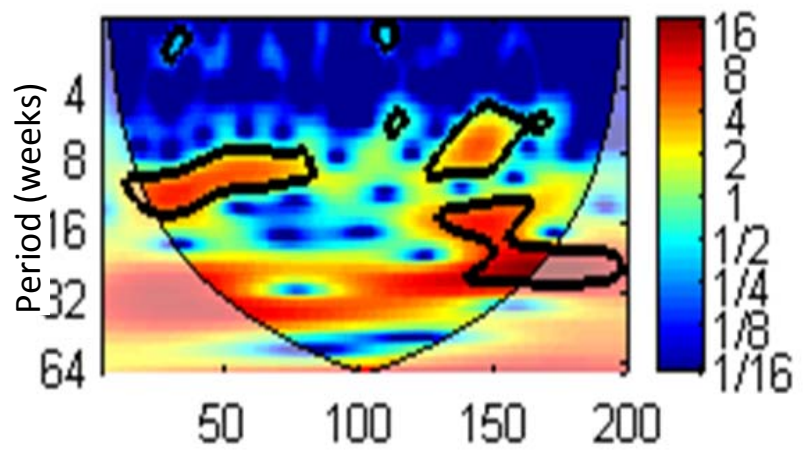

Time scale (weeks)

(b) SSMI4_L1
Figure 10. Wavelet analysis of weekly rainfall and standardized soil moisture index for layer 1 at temporal scale of 4 week (SSMI4_L1). [Note that X-axis represents duration of crop periods for different years: 2003 (1-30 weeks), 2004 (31-61 weeks), 2005 (62-87 weeks), 2006 (88-112 weeks), 2007 (113-137 weeks), 2008 (138-167 weeks), and 2009 (168-200 weeks)]. 


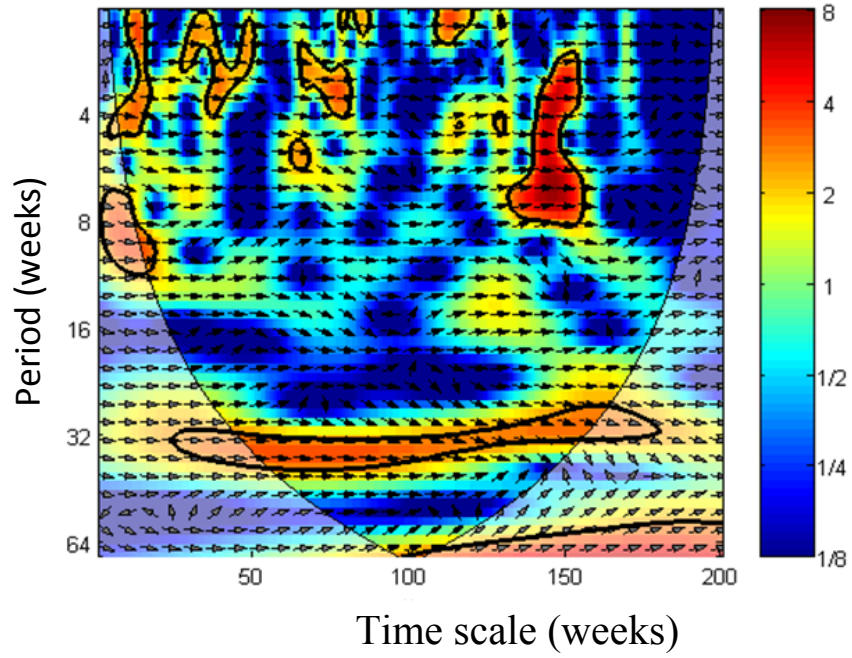

(a) SPI

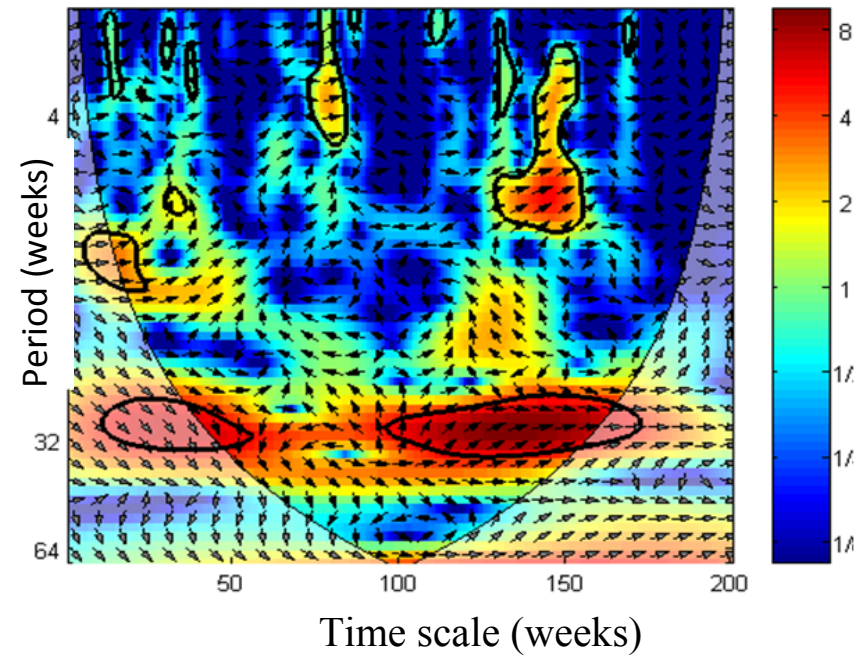

(b) SSMI1 L1

1002 Figure 11. Cross wavelet analysis between: (a) weekly rainfall and SPI1 standardized soil 1003 moisture index for layer 1 at temporal scale of 4 weeks (SSMI4_L1). [Note that X-axis represents 1004 duration of crop periods for different years: 2003 (1-30 weeks), 2004 (31-61 weeks), 2005 (62100587 weeks), 2006 (88-112 weeks), 2007 (113-137 weeks), 2008 (138-167 weeks), and 2009 (1681006200 weeks)]. 


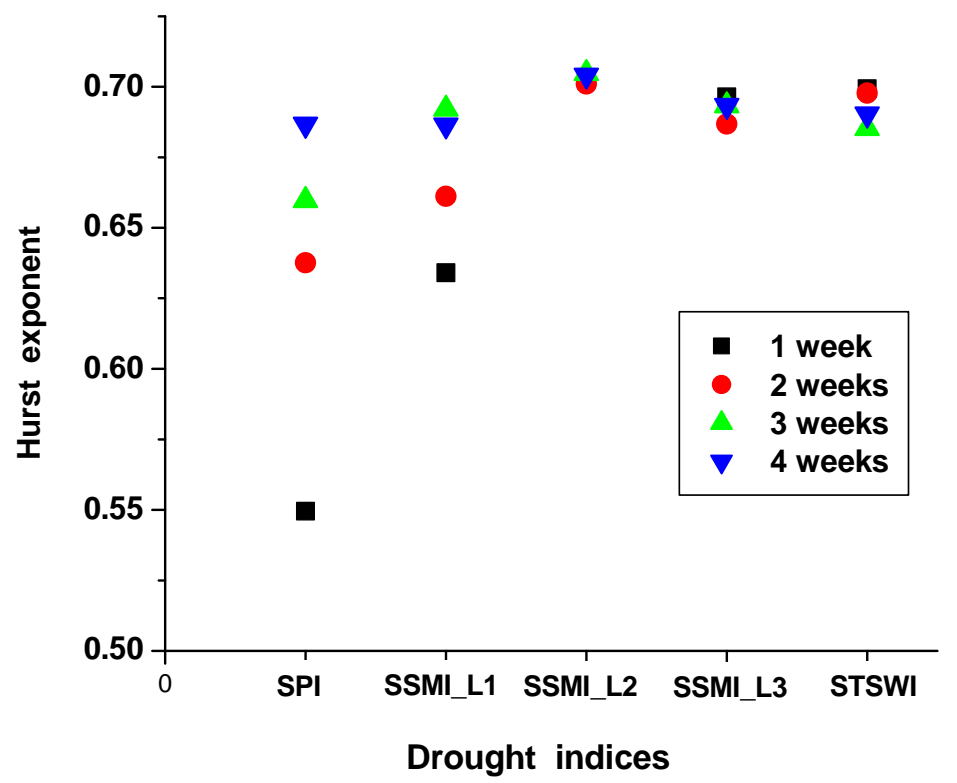


1033

1034

1035

1036

1037

1038

1039

1040

1041

1042

1043

1044

1045
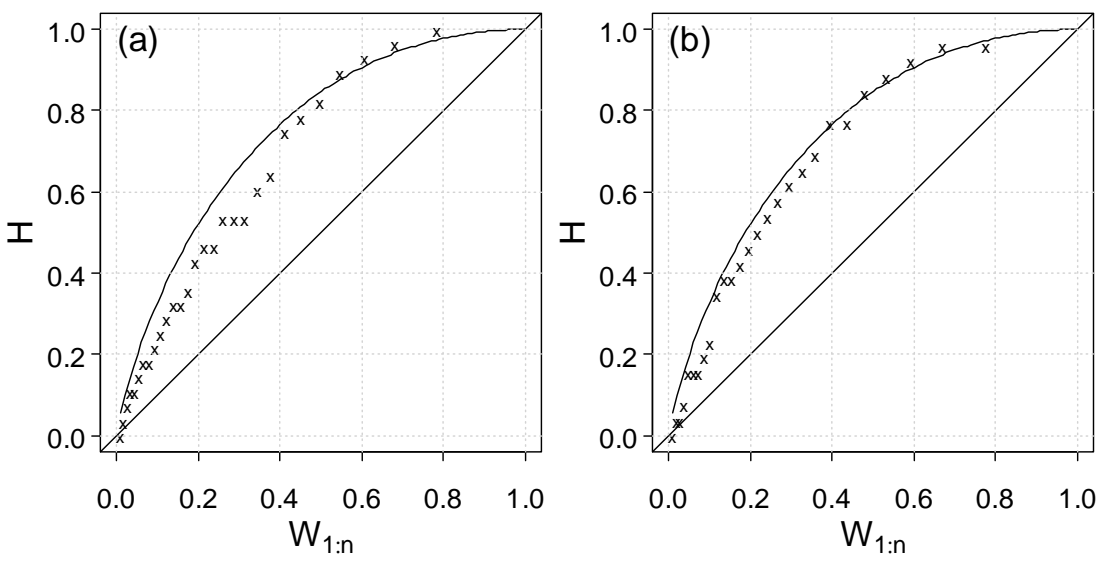

Figure 13. Kendall's plots exploring the dependence structure between drought duration and severity for (a) SPI2, (b) SSMI2_L1, (c) SMI2_L2 
1051

1052

1053

1054

1055

1056

1057

1058

1059

1060

1061

1062

1063

1064

1065

1066

1067

1068
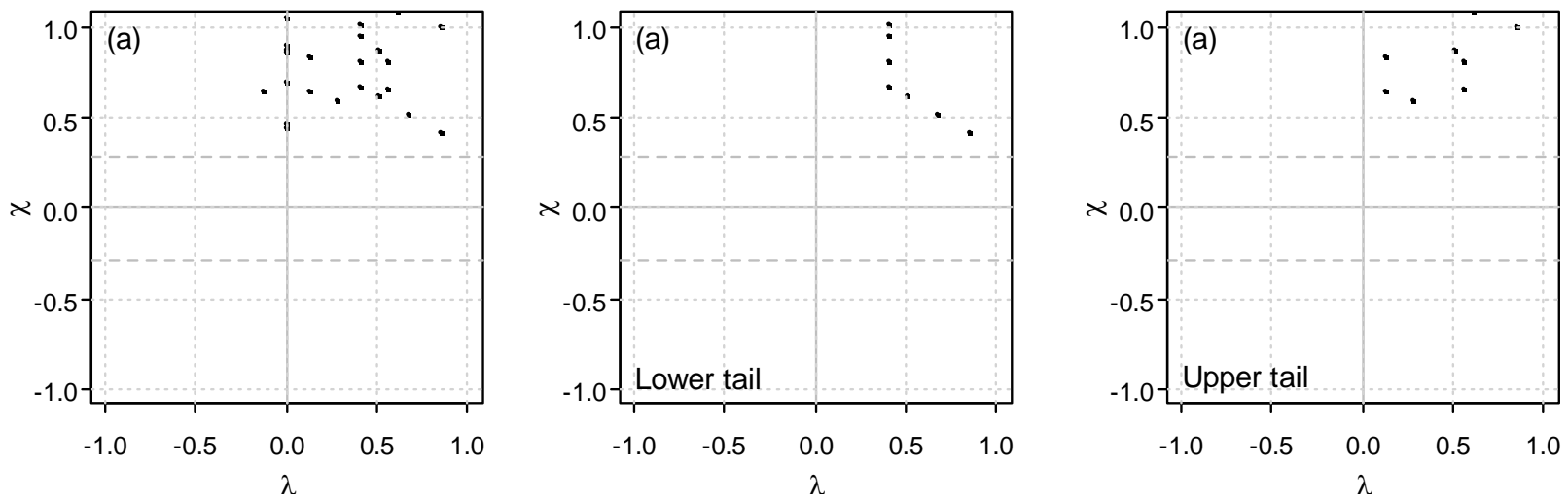

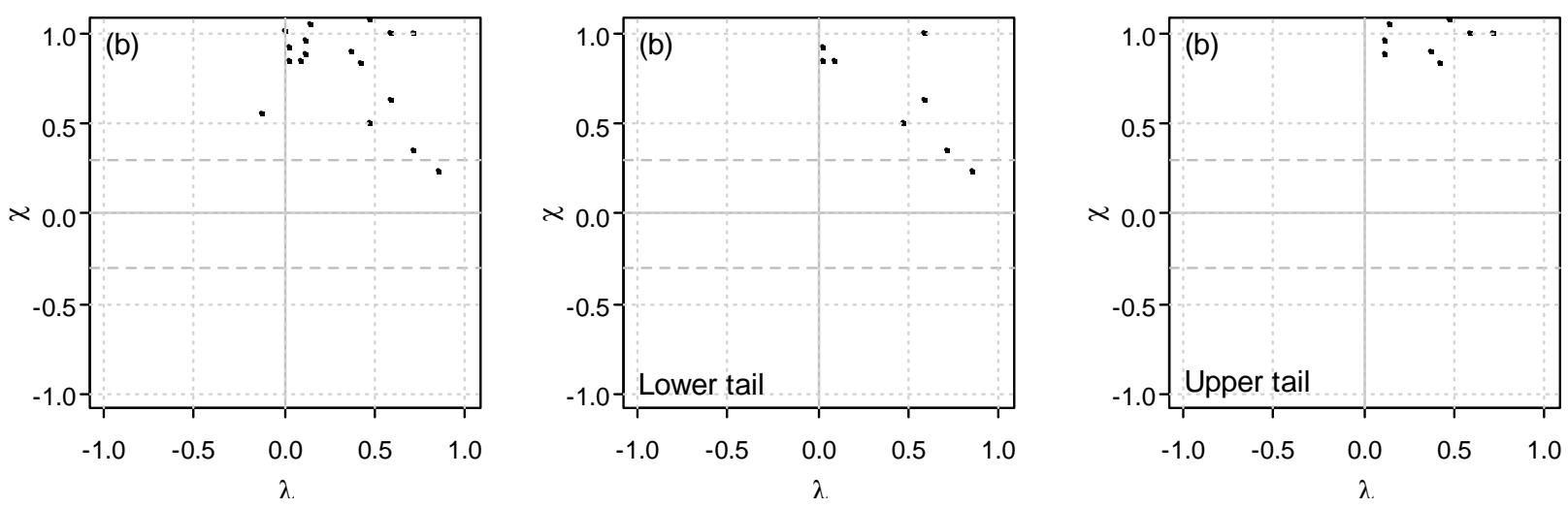

1069 Figure 14. Chi-plots exploring the dependence structure between drought duration and severity 1070 for (a) SPI2, (b) SSMI2_L1. The first column shows the complete set of data and the second and 1071 third column shows the lower and upper tail respectively.

1072

1073

1074

1075

1076

1077

1078

1079

1080

1081

1082

1083

1084

1085

1086 

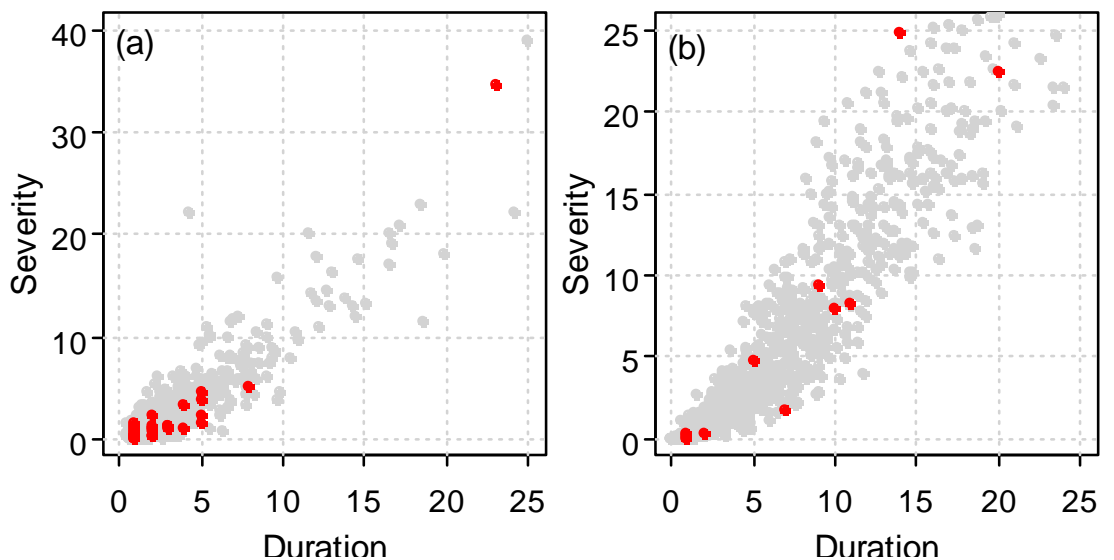

Figure 15. Comparison of observed (red dots) and simulated values (gray dots) from the 1089 most suitable copula for (a) SPI2, and (b) SSMI2_L2.

1090

1091

1092

1093

1094

1095

1096

1097

1098

1099

1100

1101 

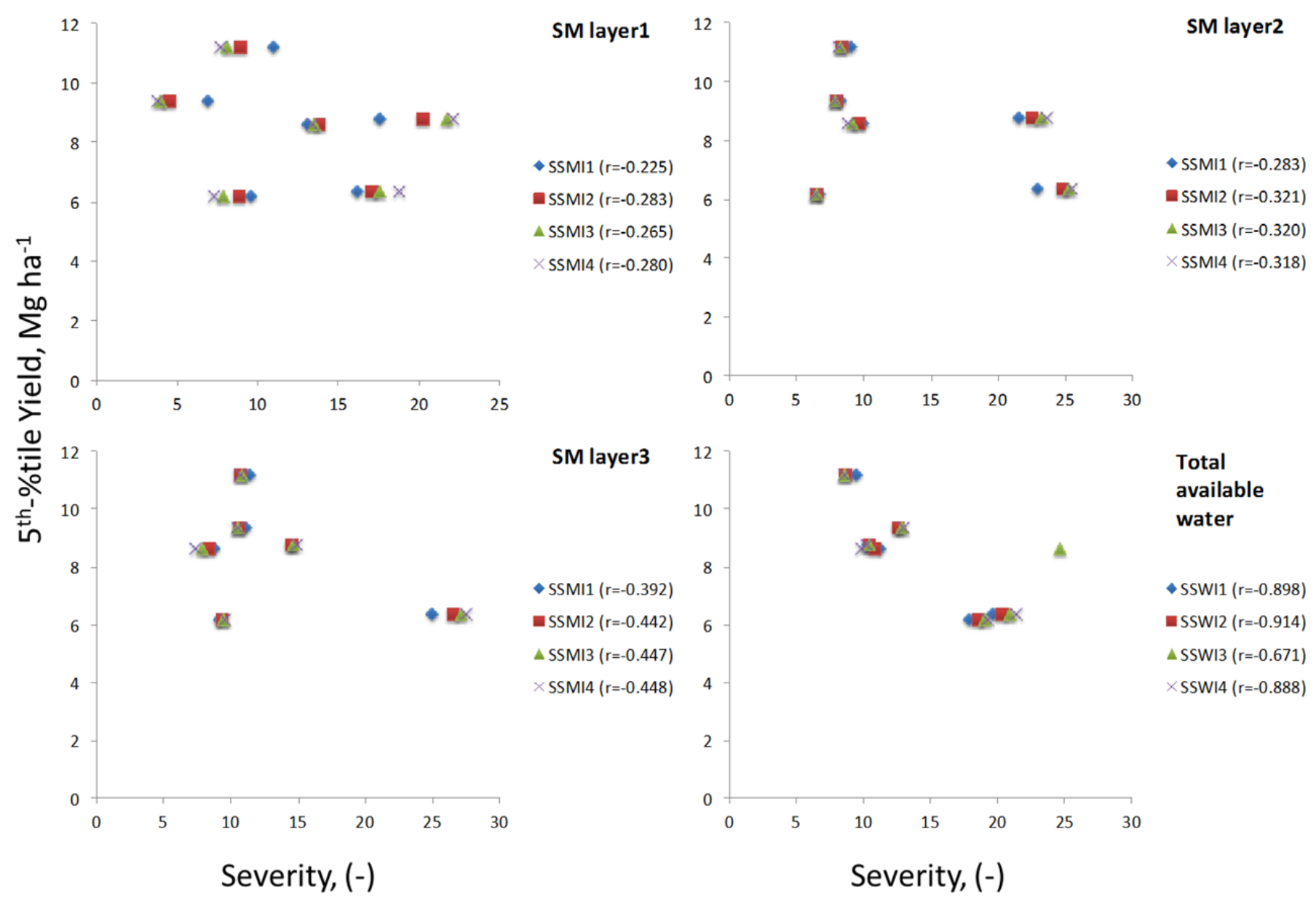

1103

Figure 16. Maize yields ( $5^{\text {th }} \%$-tile) and drought severity index relationship. The correlation coefficient 1104 values are provided in parenthesis.

1105 

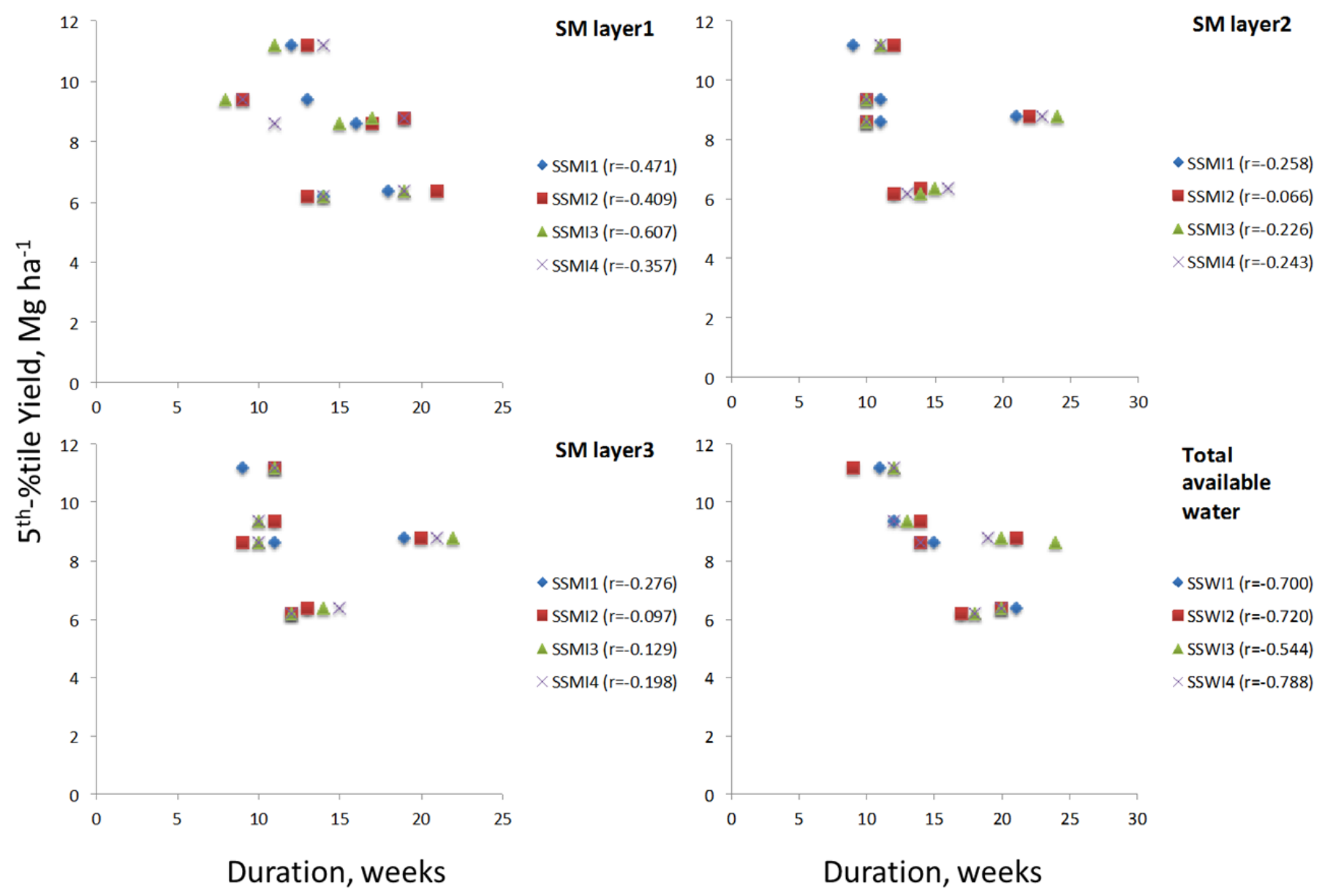

1115 Figure 17. Maize yields (5 $\%$ th 

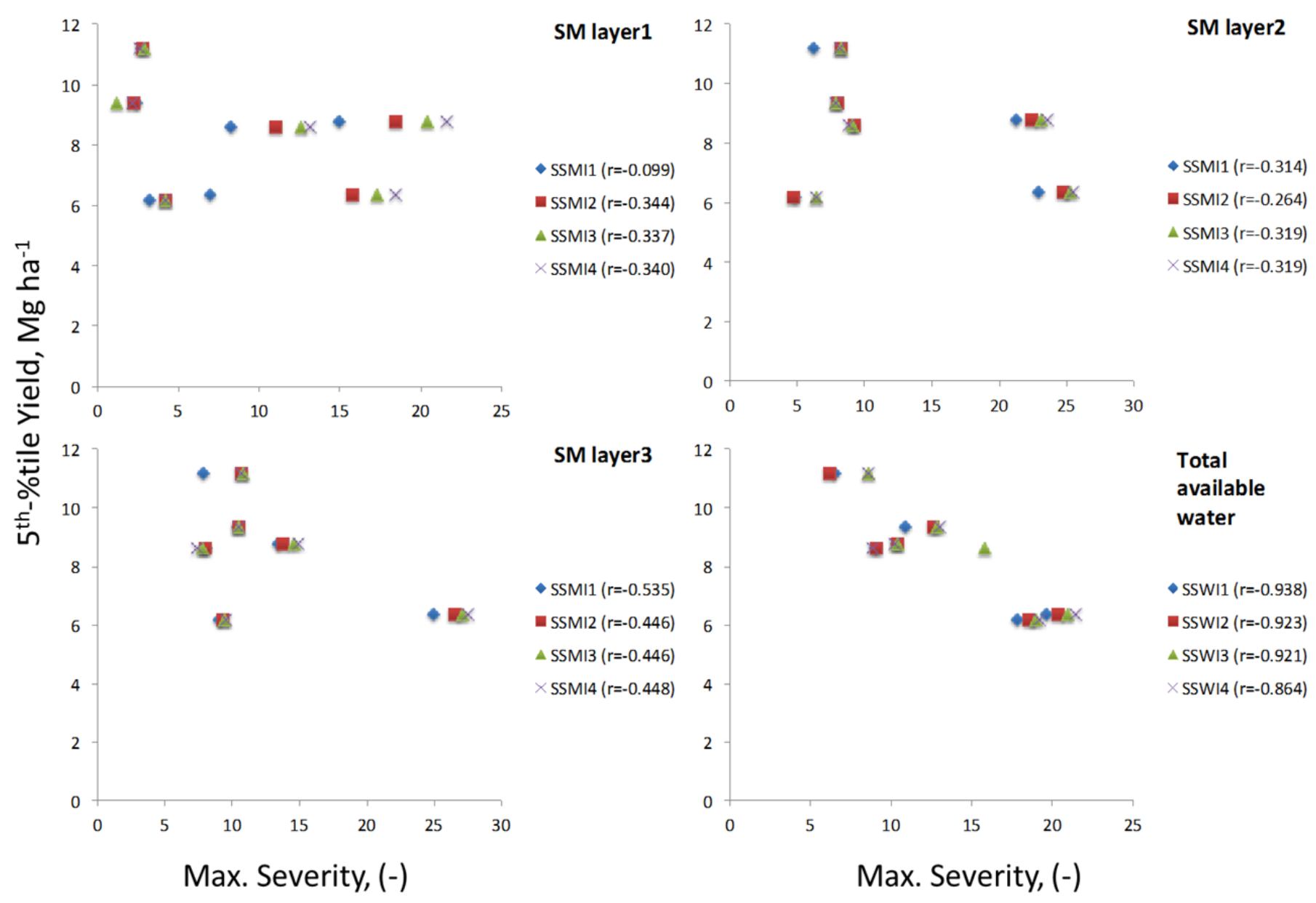

Figure 18. Maize yields ( $5^{\text {th }} \%$-tile) and drought maximum severity index relationship. 

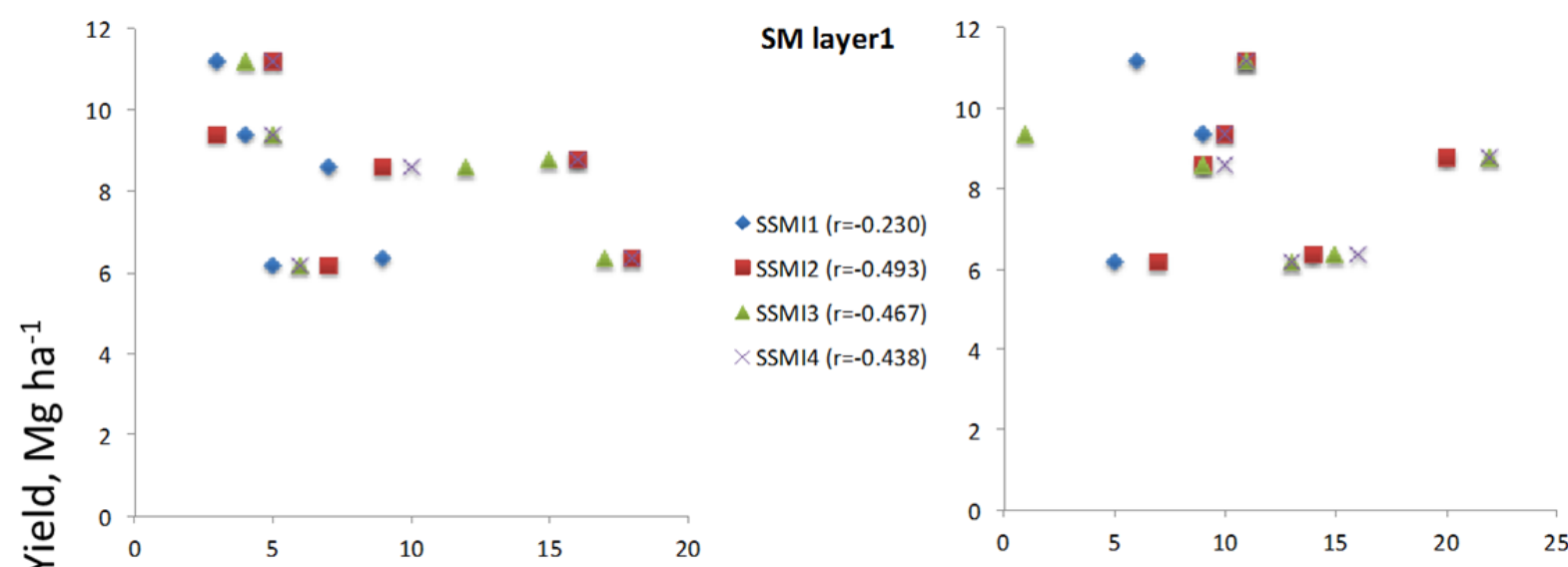

SM layer2
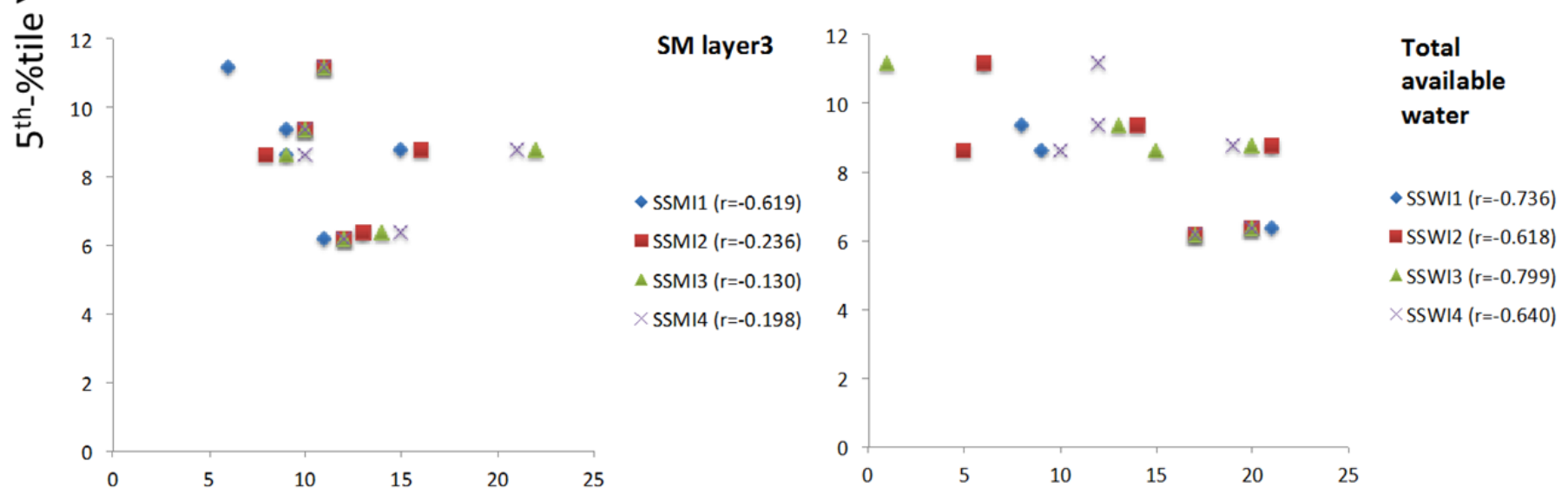

Max. Duration, weeks

Max. Duration, weeks

Figure 19. Maize yields ( $5^{\text {th }} \%$-tile) and drought maximum duration index relationship. 
1144 Table 1. Performance (average) of the crop model-data assimilation (DA) system for simulating 1145 maize yields, Story County, Iowa (after Ines et al., 2013).

\begin{tabular}{llll}
\hline Experiment & $\mathrm{R}$ & $\mathrm{MBE}, \mathrm{Mg} \mathrm{ha}^{-1}$ & $\mathrm{RMSE}^{-1} \mathrm{Mg} \mathrm{ha}^{-1}$ \\
\hline Openloop: & 0.47 & -3.7 & 4.7 \\
DA with LAI: & 0.51 & -3.2 & 4.2 \\
DA with SM: & 0.50 & -1.9 & 3.6 \\
DA with SM + LAI: & 0.65 & -2.0 & 2.9 \\
Composite best (SM + LAI, & & -1.2 & 1.4 \\
LAI): & 0.80 & & \\
\hline
\end{tabular}

$\mathrm{R}$ - Pearson's correlation

1147 MBE - Mean Bias Error

1148 RMSE - Root Mean Squared Error

1149

1150

1151

Table 2. Most appropriate copula for SPI, SSMI and SSWI

\begin{tabular}{|l|c|c|c|c|}
\hline Variable & 1 week & 2 weeks & 3 weeks & 4 weeks \\
\hline SPI & Joe & Joe & Gumbel & Gumbel \\
\hline SSMI_L1 & Joe & Joe & Gaussian & Gaussian \\
\hline SSMI_L2 & Frank & Gaussian & Gaussian & Clayton \\
\hline SSMI_L3 & Frank & Frank & Clayton & Gaussian \\
\hline SSWI & Gaussian & Clayton & Student t & Joe \\
\hline
\end{tabular}

